\author{
A Thesis by
}

Alireza Chadegani

BSc. in Mechanical Engineering, Solids Design, Iran, 2003

Submitted to the Department of Aerospace Engineering and the faculty of the Graduate School of

Wichita State University

in partial fulfillment of

the requirements for the degree of

Master of Science

May 2008 
(C) Copyright 2008 by Alireza Chadegani

All Rights Reserved 


\section{STRAIN ENERGY RELEASE RATE ANALYSIS OF ADHESIVE-BONDED COMPOSITE JOINTS WITH A PRESCRIBED INTERLAMINAR CRACK}

I have examined the final copy of this thesis for form and content and recommend that it be accepted in partial fulfillment of the requirements for the degree of Master of Science, with a major in Aerospace Engineering.

Charles Yang, Committee Chair

We have read this thesis and recommend its acceptance.

K. Suresh Raju, Committee Member

Hamid Lankarani, Committee Member 


\section{DEDICATION}

To my parents and my wife 


\section{ACKNOWLEDGEMENTS}

I express my sincere gratitude to my advisor Dr. Charles Yang for his continuous support and guidance in helping me to complete my thesis. I acquired much knowledge from him during the entire course of my master's degree. He always helped me in understanding the fundamental details and overcoming difficulties. For his valuable help, patience, and encouragement, I owe him the deepest gratitude. It's hard to express in words my thanks towards him.

I thank Dr. K. Suresh Raju and Dr. Hamid Lankarani for reviewing my thesis and making valuable suggestions. I also thank Mr. Eugene Dan-Jumbo Senior Engineer/Scientist from Northrop Grumman Corporation, San Diego, CA for his support on this my research study.

Lastly and importantly, I want to thank my parents, my wife and my sister who have been the most predominant sources of encouragement, inspiration, and love throughout my life and my studies. 


\begin{abstract}
Composite materials together with adhesive-bonding have been increasingly used in the aviation industry. Delamination is among the critical failure modes in fiber-reinforced laminated composite structures including adhesive-bonded assemblies. This thesis presents an analytical approach by taking into account the first-ply failure in adhesive-bonded composite joints subjected to axial tension. The ASTM D3165 standard test specimen geometry is followed for model development derivations. The field equations, in terms of displacements within the joint, are formulated by using the first-order, shear-deformable, laminated plate theory together with kinematics relations and force equilibrium conditions. The stress distributions for the adherends and adhesive are determined after the appropriate boundary and loading conditions are applied and the equations for the field displacements are solved. The equivalent forces at the tip of the prescribed interlaminar crack are obtained based on interlaminar stress distributions. The strain energy release rate of the crack is then determined by using the virtual crack closure technique (VCCT). The system of second-order differential field equations is solved to provide the adherend and adhesive stresses using the symbolic computation tool, Maple 9.52. Finite element analyses using the $J$-integral as well as the VCCT are performed to verify the developed analytical model. Finite element analyses are conducted using the commercial finite element analysis software ABAQUS 6.5-1. Results determined using the analytical method are shown to correlate well with the results from the finite element analyses.
\end{abstract}




\section{TABLE OF CONTENTS}

Chapter

Page

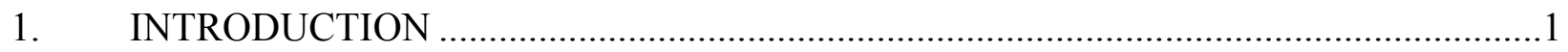

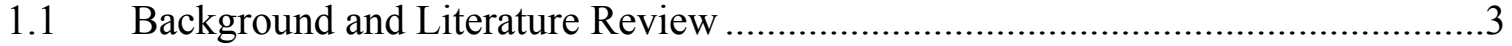

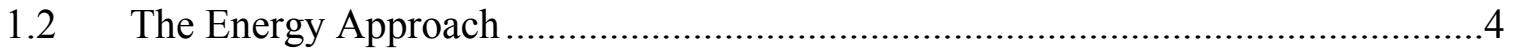

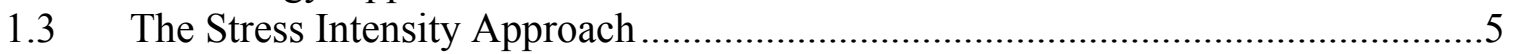

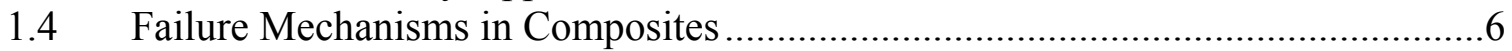

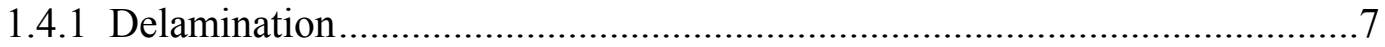

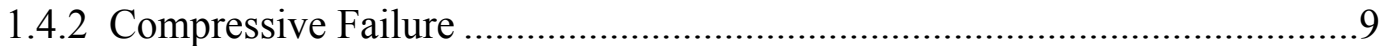

1.5 Interlaminar Toughness of Composites .......................................................... 10

1.6 Computational Fracture Mechanics ................................................................. 13

1.6.1 Overview of Numerical Methods...........................................................13

1.6.1.1 The Finite Element Method ....................................................14

1.6.1.2 The Boundary Integral Method...................................................14

1.6.2 Computational Fracture Mechanics Techniques.......................................15

1.6.2.1 Stress and Displacement Matching ...........................................15

1.6.2.2 Elemental Crack Advance......................................................15

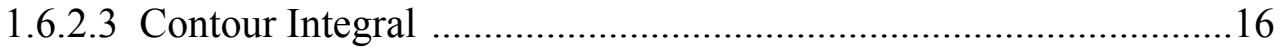

1.6.2.4 Virtual Crack Closure Technique ................................................16

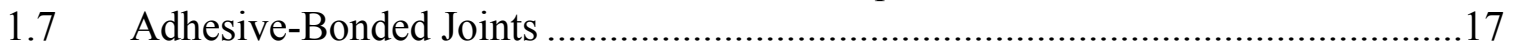

1.7.1 Failure Modes of Adhesive-Bonded Joints..............................................18

1.7.2 Analytical Approach to Evaluate Failure Modes.....................................21

1.7.3 Finite Element Approach to Evaluate Failure Modes .................................22

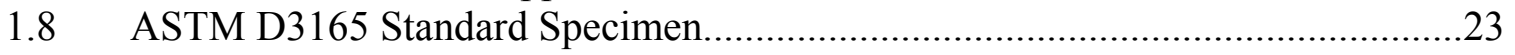

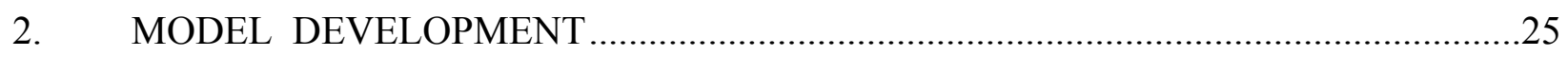

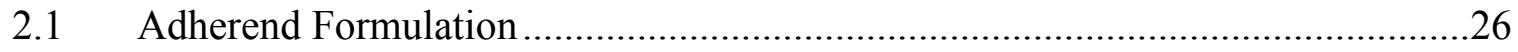

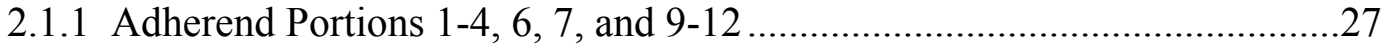

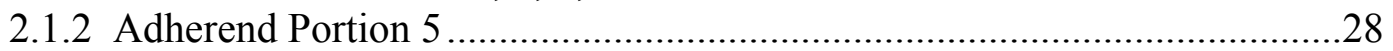

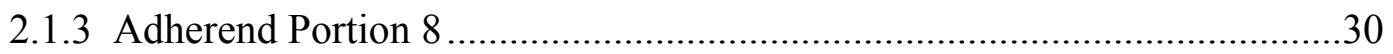

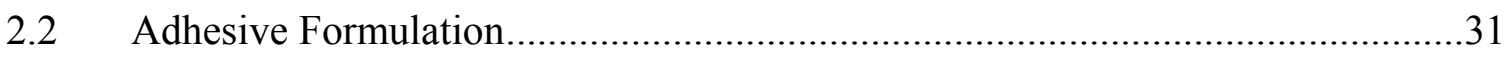

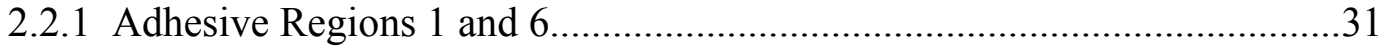

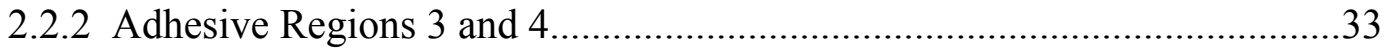

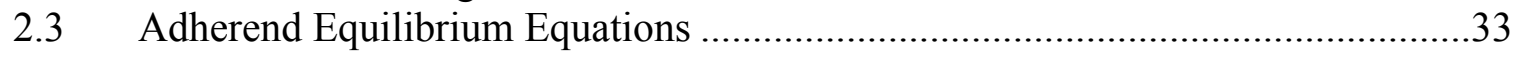

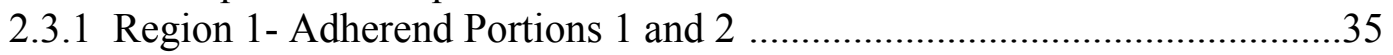

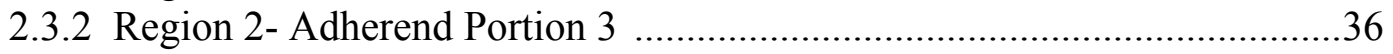

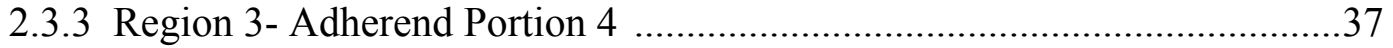

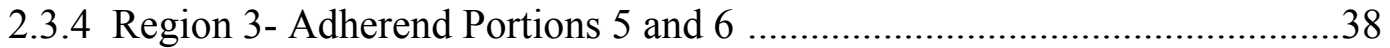

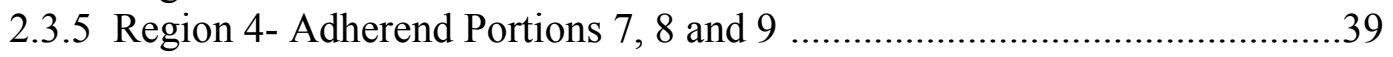

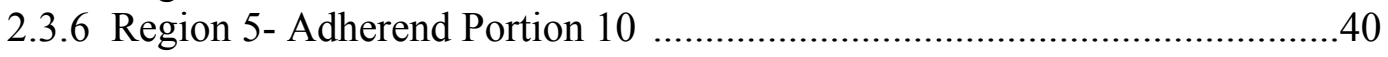

2.3.7 Region 6- Adherend Portions 11 and 12 ............................................ 40 


\section{TABLE OF CONTENTS (continued)}

Chapter

3. STRAIN ENERGY RELEASE RATE CALCULATION ........................................41

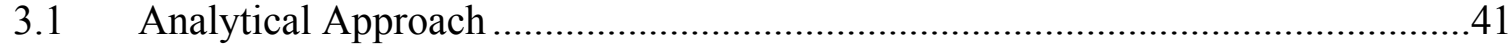

3.2 Finite Element Approach Using VCCT .....................................................46

3.3 Finite Element Approach Using $J$-Integral ..................................................47

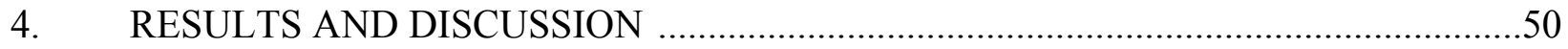

4.1 Investigation of Mesh Sensitivity in Finite Element Model ...............................51

4.2 Comparison of Mode I, Mode II, and Total Strain Energy Release Rate as a Function of Bondline Thickness ...............................51

4.3 Comparison of Mode I, Mode II and Total Strain Energy Release Rate as a Function of Initial Crack Length ..............................52

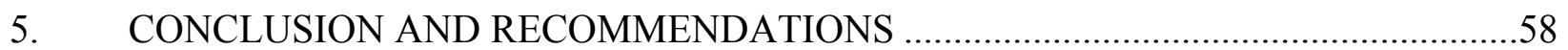

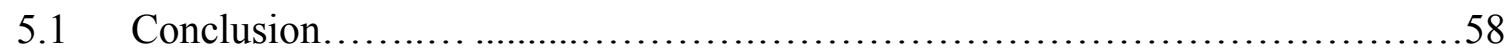

5.2 Recommendations................................................. 58

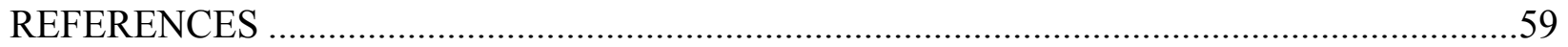

APPENDIX

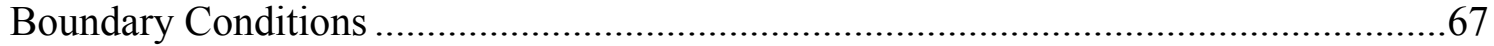




\section{LIST OF FIGURES}

Figure

Page

1.1 Comparison of the fracture mechanics approach to design with the traditional strength of materials approach

1.2 Stress near the crack-tip for elastic materials .......................................................5

1.3 Examples of mechanisms of failure in composites ................................................6

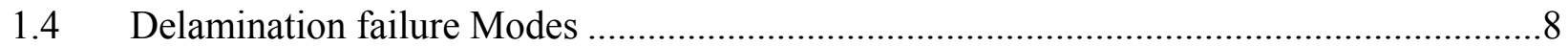

1.5 Common configurations for evaluating interlaminar fracture toughness ......................10

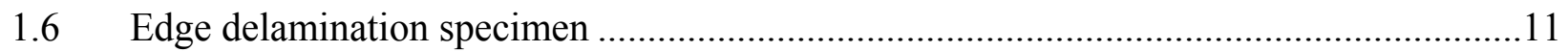

1.7 Mode I, II and mixed mode loading DCB specimens............................................... 12

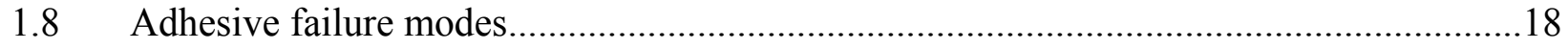

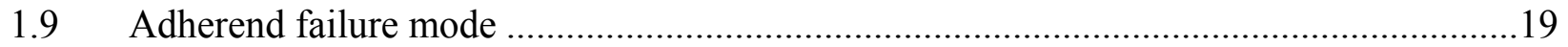

1.10 ASTM D3165 specimen configuration and deformation..........................................24

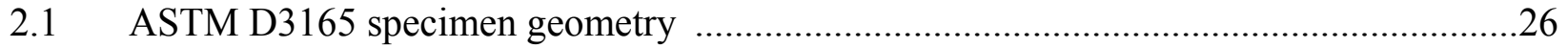

2.2 Discretized model with 12 adherend portions .......................................................27

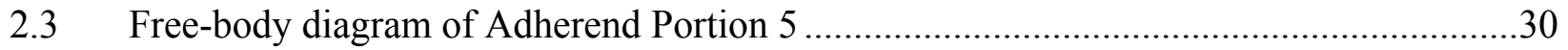

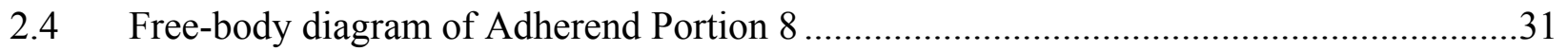

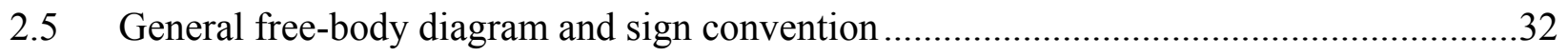

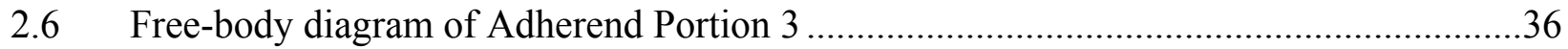

3.1 ASTM D3165 specimen with initial crack of length a ...........................................42

3.2 ASTM D3165 specimen with a virtual crack extension of length b.............................42

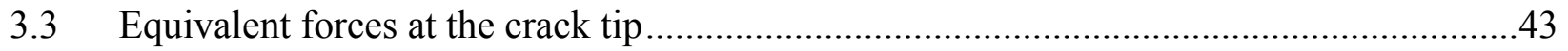

3.4 Summery of analytical approach to calculate SERR using VCCT ................................45

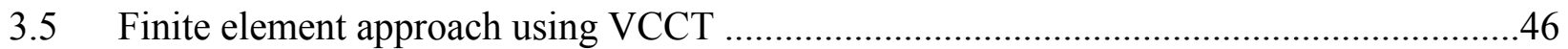




\section{LIST OF FIGURES (continued)}

Figure $\quad$ Page

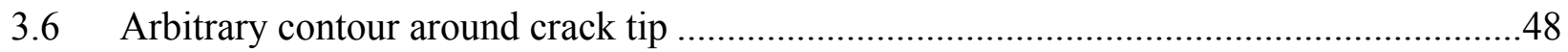

4.1 Strain energy release rate convergence of ASTM D3165 specimen versus number of elements for $\eta=0.127 \mathrm{~mm}, a=1.27 \mathrm{~mm}$, with Hysol EA $9394 \ldots \ldots . . .51$

4.2 Strain energy release rate of ASTM D3165 specimen as a function of bondline thickness for $a=1.27 \mathrm{~mm}$ with Hysol EA 9394 adhesive .53

4.3 Strain energy release rate of ASTM D3165 specimen as a function of bondline thickness for $a=1.27 \mathrm{~mm}$ with PTM\&W ES 6292 adhesive

4.4 Mode I strain energy release rate of ASTM D3165 specimen as a function of bondline thickness for $a=1.27 \mathrm{~mm}$ with Hysol EA 9394 adhesive

4.5 Mode II strain energy release rate of ASTM D3165 specimen as a function of bondline thickness for $a=1.27 \mathrm{~mm}$ with Hysol EA 9394 adhesive....

4.6 Mode I strain energy release rate of ASTM D3165 specimen as a function of bondline thickness for $a=1.27 \mathrm{~mm}$ with PTM\&W ES 6292 adhesive

4.7 Mode II strain energy release rate of ASTM D3165 specimen as a function of bondline thickness for $a=1.27 \mathrm{~mm}$ with PTM\&W ES 6292 adhesive .55

4.8 Strain energy release rate of ASTM D3165 specimen as a function of initial crack length for $\eta=0.127 \mathrm{~mm}$ with Hysol EA 9394

4.9 Strain energy release rate of ASTM D3165 specimen as a function of initial crack length for $\eta=0.127 \mathrm{~mm}$ with PTM\&W ES 6292.

4.10 Mode I strain energy release rate of ASTM D3165 specimen as a function of initial crack length for $\eta=0.127 \mathrm{~mm}$ with Hysol EA 9394

4.11 Mode II strain energy release rate of ASTM D3165 specimen as a function of initial crack length for $\eta=0.127 \mathrm{~mm}$ with Hysol EA 9394 


\section{CHAPTER 1}

\section{INTRODUCTION}

In structural applications such as aircraft and spacecraft, composite components are often fastened to other structural components using mechanical fastening devices or adhesive bondlines. While bonded joints have advantages such as low weight, distributed load transfer, and perfect sealing of the structure, the low resistance of a composite joint to interlaminar stresses limits the loads that can be transferred. Bolted joints are thus preferred for transferring high loads and have particular relevance for future primary structures. They are also preferred in situations where disassembly is required for inspection or repair. Combining these two techniques has been considered unnecessary in terms of structural performance, since the adhesive provides a stiffer load path and hence transfers the majority of the load. Mechanically fastened joints are used frequently and are one of the most important elements in composite structures such as aircraft. Regardless of the combination of material in the parts joined, the joint is a critical element whose design is vital for overall structural performance. However, the mechanical fastening of composite materials is disadvantageous due to the low bearing capacity of composite materials, overweight issues or defective structures due to improper design, insufficient load transfer and high stress concentration zones. On the other hand, compared with other joining methods, adhesive-bonded joints are preferable because

- $\quad$ distribute stress over entire bonded area

- $\quad$ allow joining materials with different thermal expansion coefficients and thermal stress level mismatch

- $\quad$ save weight and cost, provides high strength-to-weight ratio compared with mechanical fastening joints 
- $\quad$ proper and satisfying thermal and electrical properties

- $\quad$ improve the aerodynamic performance of surface

- $\quad$ reduce number of parts to be assembled

- $\quad$ eliminate the manufacturing procedures

- $\quad$ can be cured when adhesive is compatible to the resin matrix material of composite substrates

Therefore, adhesive joining is one of the most advantageous joining methods and is increasingly employed.

Applications of composite materials in the aerospace industry include all-composite components in the aircraft. Furthermore, military aircraft, missile, and spacecraft designs as well as helicopter applications are being based on the exclusive characteristics of composite materials. In addition to design, composite materials are also being applied as reinforcement for structural replacement. Unlike metallic materials, composite materials can be easily applied to form complex shapes, and they can achieve the various stiffness required in different orientations to carry various combined normal and shear loads.

Moreover, fiber reinforced composites are now being used in a wide variety of engineering structures. The concept of directional strength and stiffness has been understood sufficiently to enable efficient load bearing designs. One of the current major issues in composite structures is the understanding and prediction of damage modes and failure mechanisms. A complete knowledge of the failure mechanisms is bound to lead to the design of efficient and durable structures. 


\subsection{Background and Literature Review}

Fracture is a problem that industry has faced as a result of corrosion, dynamic loads, overloads, creep and etc. during centuries, which led to catastrophes major in aerospace and nuclear industries. Fortunately, advances in fracture mechanics have helped to effort some of the potential dangers resulted from complexity of design or technology. Designing structures to avoid fracture is not a new idea; many structures and numerous buildings commissioned by ancient Egypt, Persian and Roman Empires still standing due to ability of early engineers to hold off failure.

The Second World War separated two distinct eras in the history of fracture mechanics. Linear elastic fracture mechanics (LEFM) fairly well established, and researchers turned their attentions to crack-tip plasticity. LEFM is valid when significant plastic deformation precedes failure. Thereafter, Irwin plastic zone [1] simply extended LEFM and led to more elaborate models based on a narrow strip of yielded material at the crack tip given by Dugdale [2] and Barenblatt [3], respectively. Wells [4] proposed the displacement of the crack faces as an alternative fracture criterion when significant plasticity precedes failure. He attempted to apply LEFM to low- and medium strength structural steels. The observations led to the development of the parameter know as crack tip-opening displacement (CTOD).

Rice [5] developed another parameter to characterized nonlinear material behavior ahead of a crack. By idealizing plastic deformation as nonlinear elastic, Rice was able to generalize the energy release rate to nonlinear materials. He showed that this nonlinear energy release rate can be expressed as a line integral, which he called $J$-integral, evaluated along an arbitrary contour around the crack. Huchinson [6], and Rice and Rosengren [7] related $J$-integral to crack tip stress fields in nonlinear materials. 
Material toughness characterization is only one aspect of fracture mechanics. In order to apply fracture mechanics concepts to design, one must have a mathematical relationship between toughness, stress, crack size, and material properties. This relationship has been identified by Shih and Hutchinson [8].

Nowadays, more sophisticated models for material behavior including, time- and temperature dependent and material nonlinearity are being incorporated into fracture mechanics analyses. There are two alternative approaches to fracture analysis: the energy criterion and the stress intensity approach. Both are discussed briefly below.

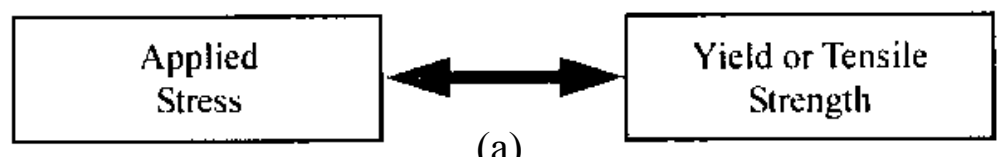

(a)

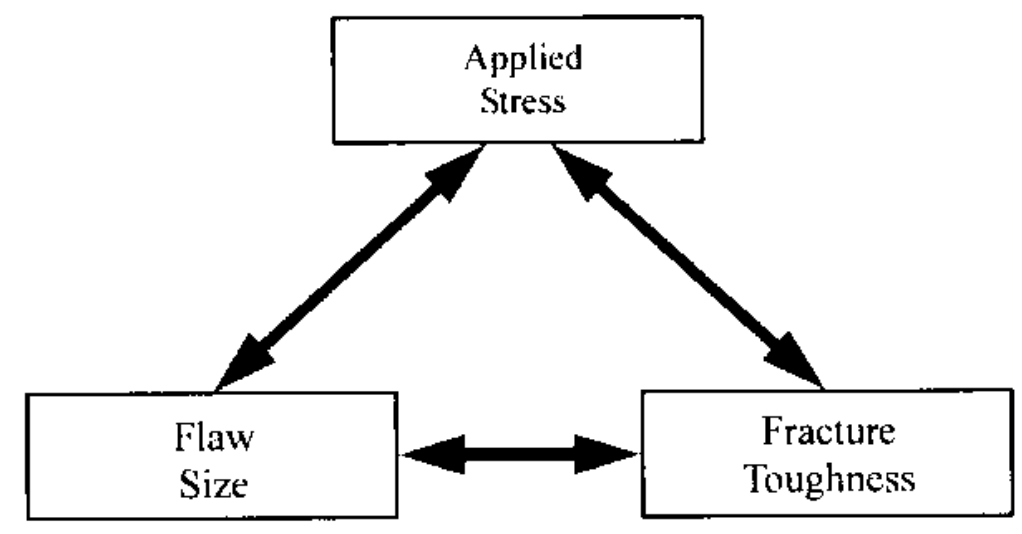

(b)

Figure 1.1 Comparison of the fracture mechanics approach to design with the traditional strength of materials approach: (a) the strength of materials approach and (b) the fracture mechanics approach [9].

\subsection{The Energy Approach}

The energy approach states that crack extension occurs when the energy release available for crack growth is sufficient to overcome the material resistance. The material resistance may include the surface energy, plastic work, or other types of energy dissipation associated with a propagating crack. Griffith [10] was the first to propose the energy criterion for fracture, Irwin 
[11] is primarily responsible for developing the present version of this approach: the energy release rate $G$ defined as the rate of change in potential energy with the crack area for a linear elastic material.

$$
G=\frac{\pi \sigma^{2} a}{E}
$$

where $E$ is Young's modulus, $\sigma$ is the remote stress, and $a$ is the half-crack length.

\subsection{The Stress- Intensity Approach}

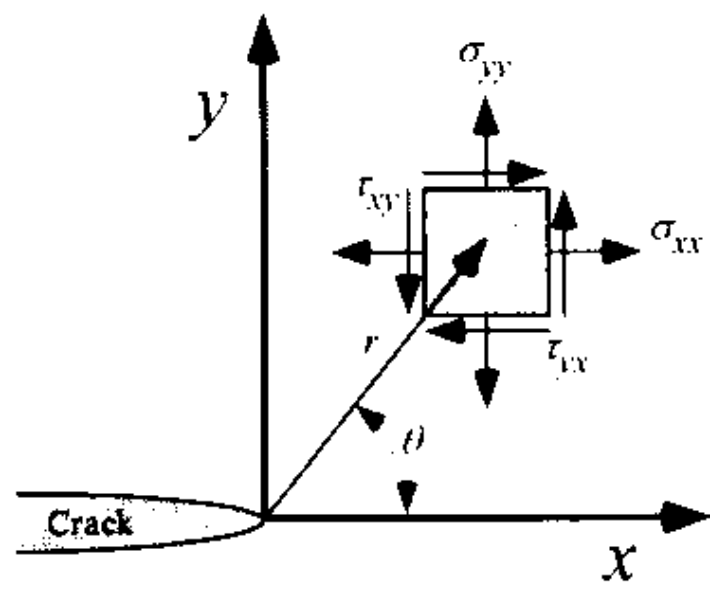

Figure 1.2 Stress near the crack-tip for elastic materials [9].

Figure 1.2 schematically shows an element near the crack tip of a crack in an elastic material, together with the in-plane stresses on this element. If one assumes that the material fails locally at some intensity $K_{I C}$, therefore the driving force for fracture $K_{I}$ should be equal to material resistance, $K_{I C}$.

$$
K_{I}=\sigma \sqrt{\pi a}
$$

Comparing equations (1.1) and (1.2) results in following relationship

$$
G=\frac{K_{I}^{2}}{E}
$$


Both approaches have been applied to metal and nonmetal structures, comparing with the fracture of metals, theoretical framework is not yet fully developed for nonmetals. Although many aspects of fracture toughness testing is similar for metals and nonmetals, there are some differences such as highly rate dependent, and violation of continuum assumptions [9]. In the most studies, energy method has been widely used concerning simplicity of the formulation for complex geometries.

\subsection{Failure Mechanisms in Composites}

Many have attempted to apply fracture mechanics to fiber reinforced composites, and have achieved some success. Conventional fracture mechanics methodology assumes a single dominant crack that grows in size but and orientation remains the same. Fracture of a fiber reinforced composite, however, is often controlled by numerous cracks distributed throughout the material, rather than a single crack. There are situations where fracture mechanics is appropriate for composites, but it is essential to recognize the limitations of theories.

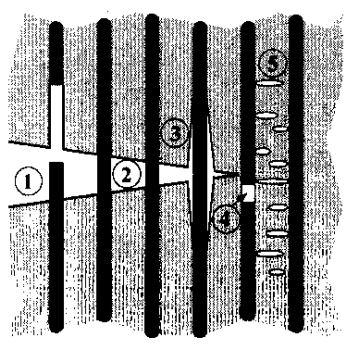

(a)

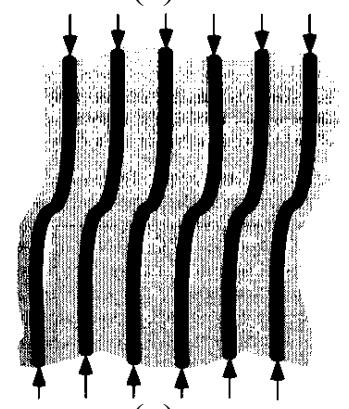

(c)

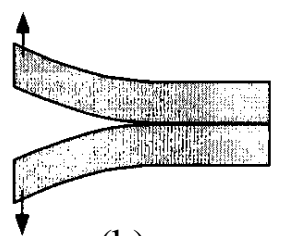

(b)

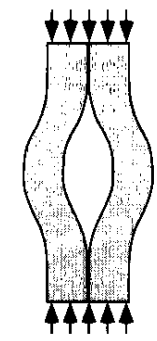

(d)

Figure 1.3 Examples of mechanisms of failure in composites: (a) In-plane damage, (b) Delamination, (c) Microbuckling, and (d) Buckling delamination [9]. 
Figure 1.3 shows various failure mechanisms in fiber reinforced composites. One advantage of composite materials is that fracture seldom occurs catastrophically without warning, but tends to be progressive, with subcritical damage widely distributed through the material. Tensile loading (Fig. 1.3(a)) can produce matrix cracking, fiber bridging, fiber rupture, fiber pull out, and fiber/matrix debonding. Ultimate tensile failure of a fiber reinforced composite often involves several of these mechanisms. Out-of-plane stresses can lead to delamination (Fig. 1.3(b)) because the fibers do not contribute significantly to the strength in this direction. Compressive loading can produce the microbulking of fibers (Fig. 1.3(c)); since the polymer matrix is soft compared to the fibers, the fibers are unstable in compression. Compressive loading can also lead to macroscopic delamination buckling (Fig. 1.3(d)), especially if the material contains a preexisting delaminated region or void.

\subsubsection{Delamination}

Out-of-plane tensile stresses can cause failure between plies. Stresses that lead to delamination could result from the structural geometry, such as if two composite planes are joined in a " $T$ " configuration. Out-of-plane stresses, however, arise from an unexpected source. Mismatch in Poisson's ratios between plies result in shear stresses in the fiber plane near the ply interface. These shear stresses produce a bending moment that is balanced by stress in $z$ direction. For some lay up sequences, substantial out-of-plane tensile stresses occur at the edge of the panel, which can lead to the formation of a delamination crack.

Although the assumption of increase in crack length of a dominant crack often does not apply to the failure of composite materials, such an assumption is appropriate in the case of delamination. Consequently, fracture mechanics has been very successful in characterizing this failure mechanism. 
Delamination can occur in both Mode I and Mode II. The interlaminar fracture toughness, which is usually characterized by a critical energy release rate, is related to the fracture toughness of the matrix material. The matrix and composite toughness are seldom equal, however, due to the influence of the fibers in the latter.

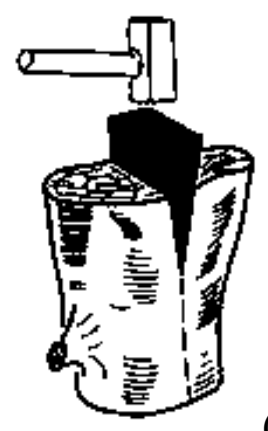

(a)
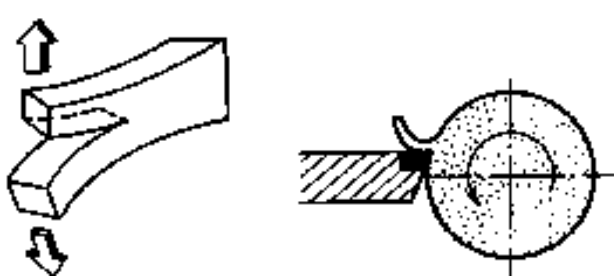

(b)

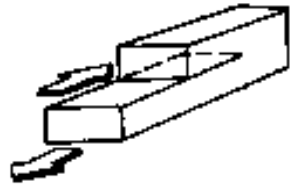

Figure 1.4 Delamination failure Modes: (a) Mode I and (b) Mode II [12].

For brittle thermosets, the composite has a higher toughness that the neat resin, but the effect is reversed for high toughness matrices. Attempts to increase the composite toughness through tougher resins have not met proper results, because only a fraction of the resin toughness transferred to the composite. With respect to the fracture of tough matrices, one possible explanation for the lower relative toughness of the composite is that the latter is limited by the fiber/matrix bond, which is weaker than the matrix material. Experimental observations, however, indicate that fiber constraint is a more likely explanation [13]. In high toughness polymers, a shear or wrinkle zone forms crack-tip front. If the toughness is sufficient for the size of the damage zone to exceeds, the fiber spacing, the fiber restrain the crack-tip yielding, resulting in a smaller zone than in the neat resin. The smaller the damage zone is, the lower the fracture energy will be between plies.

Mode II delamination is possible, but Mode I critical strain energy release rate is typically 2 to 10 higher than Mode II critical strain energy release rate, these disparity typically occurs in brittle matrices . 
In-situ fracture experiment in an scanning electron microscopy (SEM) shows long and slender damage zones containing numerous microcracks from ahead of the crack-tip [9].

In Ductile matrices, the appearance of the Mode II damage zone is similar to the Mode I case, and the difference between their critical values is not as much as for brittle matrices [9].

\subsubsection{Compressive Failure}

High-modulus fibers provide excellent strength and stiffness in tension, but limited value for compressive loading. According to the Euler buckling equation, a column of length $L$ with a cross-section moment of inertia $I$, subjected to a compressive force $P$, becomes unstable when

$$
P \geq \frac{\pi^{2} E I}{L^{2}}
$$

assuming the loading is applied on the central axis of the column and the ends are unstrained. Early attempts [14] to model fiber buckling in composites incorporated an elastic foundation into the Euler buckling analysis. This let to the following compressive failure criterion for unidirectional composites.

$$
\sigma_{c}=\mu_{L T}+\pi^{2} E_{f} V_{f}\left(\frac{r}{L}\right)^{2}
$$

where $\mu_{L T}$ is the longitudinal-transverse shear modulus of the matrix and $E_{f}$ is fibers Young's modulus. Problems with this prediction are that it assumes that the response of the material remains elastic; matrix yielding is likely for large lateral displacement of the fibers. Additionally, fiber buckling is local, while it considers global fiber instability. Moreover, fiber waviness is a fundamental assumption in fiber composites; that is, fibers are seldom perfectly straight. Recent investigations have incorporated the matrix nonlinearity and fiber waviness [1517]. Microbuckling is not the only mechanism for compressive failure. Delamination buckling has been observed in composites that haven subjected to impact damage. 


\subsection{Interlaminar Toughness of Composites}

Interlaminar fracture is one of the few instances where fracture mechanics formulation is applicable to fiber reinforced composites on global scales. A zone of delamination can be treated as a crack; the resistance of the material to the propagation of this crack id the fracture toughness. Since the crack typically growth is unique in size growth.

A number of researchers have performed delamination experiments on fiber reinforced composites over the past years [18-20]. Several standards and test methods for measuring interlaminar fracture toughness have been published recently. ASTM D5528, for instance, conducts with Mode I delamination testing [21].

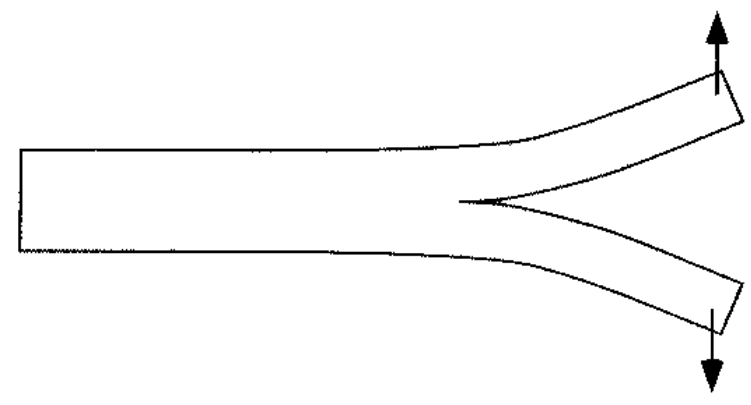

(a)

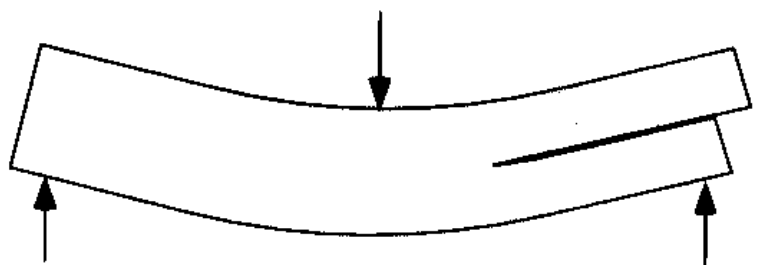

(b)

Figure. 1.5 Common configurations for evaluating interlaminar fracture toughness: (a) double cantilever beam specimen and (b) end-notched flexure specimen [9].

Figure 1.5 illustrates two common specimen configurations for interlaminar fracture toughness measurements. The double cantilever beam (DCB) specimen is the most common configuration for this type of test. One advantage of this specimen geometry is that it permits measurements mixed mode fracture toughness. The end-notched flexure (ENF) specimen has the same geometry as the DCB specimen, but it loaded in three-point bending, which imposes Mode II displacements of the crack faces. 


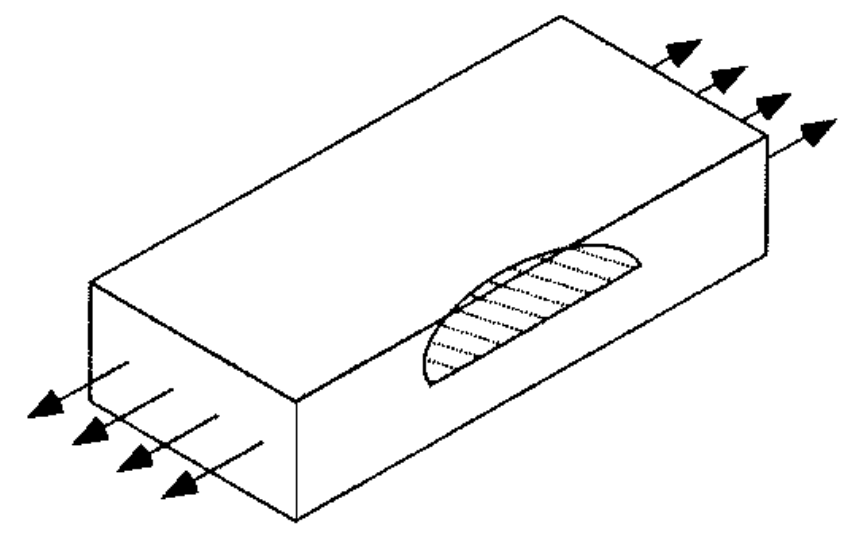

Figure 1.6 Edge delamination specimen [9].

The edge delamination specimen simulates the conditions in actual structure. Knowing that tensile stresses normal to the ply are highest at the free edges; thus delamination zones often initiate at the edges of panel.

The initial flaw in a DCB specimen is normally introduced by placing a thin film between plies prior to molding. The film should be coated with a release agent so that it can be removed prior to testing.

The DCB specimen can be tested in Mode I, Mode II, or mixed mode conditions, and the strain energy release rate of this configuration can be obtained from the beam theory.

For mixed Mode loading, elastic beam theory leads to the following expression

$$
G_{I}+G_{I I}=\frac{P_{I}^{2} a^{2}}{B E I}+\frac{3 P_{I I}{ }^{2} a^{2}}{4 B E I}
$$

where $P$ is applied force, $a$ is crack length, $E$ is Young's modulus, $B$ is DBC width, and $I$ is cross sectional moment of inertia. Mixed mode loading can be achieved by unequal upper and lower tensile loading (see Fig. 1.7-c). 


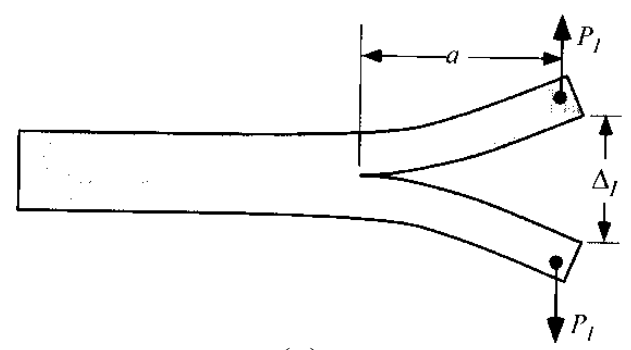

(a)

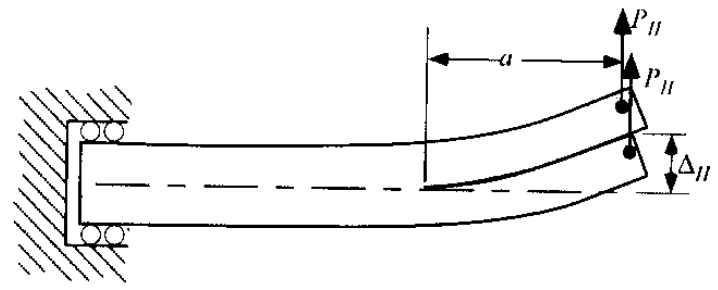

(b)

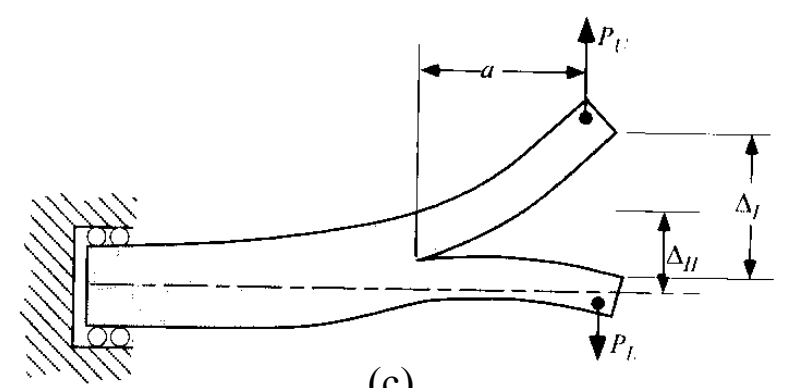

(c)

Figure 1.7 Mode I,II and mixed mode loading DCB specimens: (a) Mode I, (b) Mode II, and (c) Mixed mode [9].

The applied load can be given as follows

$$
\begin{gathered}
P_{I}=\left|P_{L}\right| \\
P_{I I}=\frac{\left|P_{U}\right|-\left|P_{L}\right|}{2}
\end{gathered}
$$

where $P_{U}$ and $P_{L}$ are the upper and lower loads, respectively. The energy release rate can be estimated from the incremental area inside the load-displacement curve, divided by the change in crack area

$$
G=\frac{\Delta U}{B \Delta a}
$$




\subsection{Computational Facture Mechanics}

Computers have had an enormous influence in virtually all branches of engineering, and fracture mechanics is not an exception. Numerical modeling has become an indispensable tool in fracture analysis, since relatively few practical problems have closed-form analytical solutions.

Stress-intensity solutions literally have been published for hundreds of configurations, the majority of which were inferred from numerical models. Elastic-plastic analyses to compute the $J$-integral and crack-tip-opening displacement (CTOD) are also becoming popular. In addition researches are applying advance numerical techniques to special problems, such as ductile crack growth, interlaminar fracture, and dynamic fracture.

Fast developments in computer technology are primarily responsible for extensional growth in application of computational fracture mechanics (CFM). Hardwares more importantly computer programmings lead to more efficient algorithms which reduced times in solution of fracture mechanics. Commercial numerical analysis codes become more user-friendly, and many codes and many of them have included fracture mechanics [9].

\subsubsection{Overview of Numerical Methods}

It is often important to determine the distribution of stresses and strains in a body that is subjected to external load or displacement. Westegard [22] and Williams [23] used analytical approach to derive solutions for stress and strain near the tip of the sharp crack in an elastic material.

A variety of numerical techniques have been applied to problems in solid mechanics, including finite difference, finite element, and boundary integral equation method. In resent years, the latter two numerical methods have been applied almost exclusively. 


\subsubsection{The Finite Element Method}

In the finite element method, the structure of interest is subdivided into discrete shapes, elements. The most common types include one-dimensional, two-dimensional plane stress and plane strain elements, and three-dimensional bricks or tetrahedrons. Isoparametric continuum elements for two-dimensional element together with local and global coordinate axes mostly are utilizing to map from one coordinate system to another. Shape functions are polynomials that interpolate field quantities within the element. The degree of polynomial is dependent on nodes. Using the stiffness finite element method will lead to the nodal displacement and furthermore, to strain and stress distributions [9].

\subsubsection{The Boundary Integral Method}

Most problems in nature can not be solved without appropriate boundary conditions. In the general case, the surface of a body can be divided into two regions: region where displacements are specified, and region where tractions are specified. Given these boundary conditions, it is theoretically possible to solve the problem within the body. Boundary integral equation (BIE) is a very powerful technique for solving for unknown tractions and displacements on the surface. This approach can also provide solutions for internal field quantities, but finite element analysis is more efficient for this purpose.

The boundary integral method is usually applied to linear fracture elastic problems, but this technique can also be utilized for elastic-plastic analysis. As with the finite element analysis finite element method, nonlinear BIE analyses are typically performed incrementally, and the strain-stress relationship is assumed to be linear within each increment [9]. 


\subsubsection{Computational Facture Mechanics Techniques}

Several approaches have been investigated for inferring fracture mechanics parameters from numerical analysis. Most of the earlier techniques have been made obsolete by more recent accurate and efficient methods. The point matching entails inferring the stress-intensity factor from the stress or displacement field in the body, while energy method computes the energy release rate in the body and relates it to stress-intensity factor. Most of the techniques can be implemented with either finite element or boundary element methods [9].

\subsubsection{Stress and Displacement Matching}

The stress-intensity factor can be estimated from stress in front of the crack tip or displacements behind the crack tip. The stress-intensity factor can be inferred by plotting from the crack tip displacement versus local coordinate system. The boundary collocation method $[23,24]$ is an alternative point-matching technique for stress intensity factor. This approach entails finding stress functions that satisfy the boundary conditions at various nodes. The minimum number of nodes used in the analysis corresponds to the number of unknown coefficients in the polynomials. Early researchers in CFM attempted to reduce the mesh size requirements for point-matching analyses by introducing $r^{-1 / 2}$ singularity [9].

\subsubsection{Elemental Crack Advance}

The energy release rate can be inferred from the rate of change in global potential energy with crack growth. If two separate numerical analyses of a given geometry are performed, one with the initial crack $a$, and other with crack $a+\Delta a$, the energy release rate is given as

$$
G=-\left(\frac{\Delta \Pi}{\Delta a}\right)_{\text {fixed boundary condition }}
$$

This technique requires minimal postprocessing, since total strain energy is output by many commercial analysis codes. This method is more efficient than the point-matching 
method, since there is no need to refine the mesh. One advantage of the elemental crack advance method is that multiple solutions are required, whereas in other methods, the desired crack-tip parameter infer from a single analysis.

\subsubsection{Contour Integral}

The $J$-integral can be evaluated numerically along a contour surrounding the crack tip. The advantages of this method are that it can be applied both to linear and nonlinear problems, and path independent enables the user to evaluate $J$ at a remote contour, where numerical accuracy is greater. For problems that include path-independent plastic deformation or thermal strains, it is still possible to compute $J$ at a remote contour.

More recent numerical formulations for evaluating $J$ apply an area integration for twodimensional problems and a volume integration for three-dimensional problems. Area and volume integrals provide much better accuracy than contour and surface integrals.

$$
J=\lim _{\Gamma_{o} \rightarrow 0} \int_{\Gamma_{o}}\left[(w+T) \delta_{1 i}-\sigma_{i j} \frac{\partial u_{j}}{\partial x_{1}}\right] n_{i} d \Gamma
$$

Where $J$ is the $J$-integral value, $T$ is the kinetic energy density, $u$ is the displacement function, $\sigma$ is the stress function and, $w$ is the mechanical strain which is sum up elastic and plastic components, the integral has been evaluated contour, $\Gamma$ around the crack-tip [9].

\subsubsection{Virtual Crack Closure Technique}

Parks [25] and Helen independently proposed the Virtual Crack Closure Technique using finite element method. deLorenzi $[26,27]$ improved the method by considering the strain energy release rate of a continuum. The main advantages of the continuum approach are

- the methodology is not restricted to the finite element method

- does not need numerical differencing 
For two-dimensional problems, the virtual crack closure formulation of strain release rate requires an area integration, while three-dimensional problems need a volume integration. Therefore, this approach is easier to implement numerically and is more accurate than contour and surface integrations. Numerical implementation of the virtual extension method entails applying a virtual displacement to nodes within a specified contour.

\subsection{Adhesive-Bonded Joints}

Adhesive-bonded technology has been employed for many decades; most importantly it can be used to effectively join similar and dissimilar materials to form load-bearing engineering structural joints (Adams et al., 1997). Adhesive bonding can be particularly effective when used to join thin metallic or laminated composite sheets in the context of efficiency transferring load. To efficiently employ an adhesive joint in practice, it is essential to predict failure and strength accurately. Single lap joint (SLJ) is probably the simplest configuration that has been studied by using numerical and experimental approaches.

The single lap joint is representative of a number of joint systems used in actual structures as well as in test specimens. In the case of joints in which composite adherends are present, the analyses have preliminary used strength of materials approaches, with the adherends treated as Euler beam-on-elastic foundations. In the Euler-beam approach, transverse shear and thickness normal deformations in the adherend are ignored. In the most simplified analyses, the adherend is treated as a membrane in which only stretching deformations are considered, while in the well known Goland and Reissner approach, adherend bending effects are included. Erdogan and Ratwani membrane response approach in conjunction with nonlinearity and other adverse environmental and thermal stresses makes the complete reliance on bonded joints difficult [28]. 
In the case of adhesive joints, analyses have involved either closed form or finite-element approaches. Closed-form analyses have use classical beam models for adherend ignoring transverse thickness normal and shear deformations. More elaborate analyses based on twodimensional continuum analyses are not readily available for the case of composite joints. The application of three-dimensional stress analyses and material nonlinearity in the; laminate appear to be essential for failure investigation.

\subsubsection{Failure Modes of Adhesive-Bonded Joints}

In order to analyze the failure behavior of adhesive-bonded composite joints, full understanding of failure modes should be investigated. With respect to the location the lowest load carrying capacity, adhesive-bonded joints may fail by the following modes: (i) adhesion failure, (ii) cohesion failure, (iii) adherend compressive failure, (iv) out-of-plane failure in the form of interalaminar and interlaminar failure [29-31]. Figure 1.8 illustrates all adhesive failure modes.

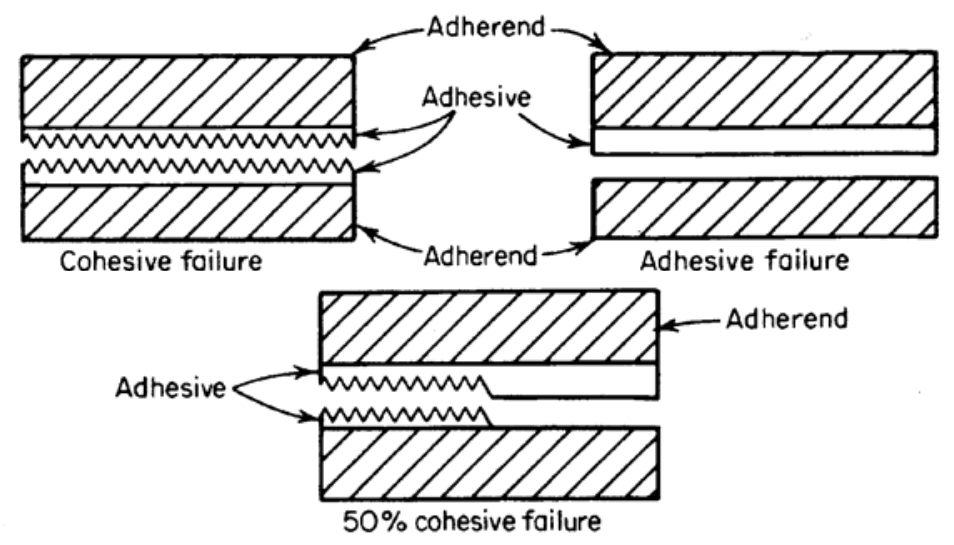

Figure 1.8 Adhesive failure modes [32].

For metal adherend, mostly cohesive failure occurs, but not the adhesive failure at the interface of adherend/adhesive [33]. However, due to adherend/adhesive Poisson's ratio mismatch in composites adherend both adhesive and cohesive failures have been observed [34]. 
Out-of-plane failure in adhesive-bonded composite joints often initiate in the form of matrix cracks or delaminations. Matrix cracks refer to interalaminar failures whereas delaminations (Fig. 1.9) refer to interlaminar failures [34].

Matrix cracks usually occur within laminates where the fibers run at an angle to the primary load direction. Hence, such matrix cracks are also called transverse cracks. Based on the location and direction of growth, two distinct types of delamination can be discerned. These two types are called edge delamination and local or transverse crack tip delamination. Edge delaminations initiate at the load free edges of the laminate whereas local delaminations start from a transverse matrix crack [35].

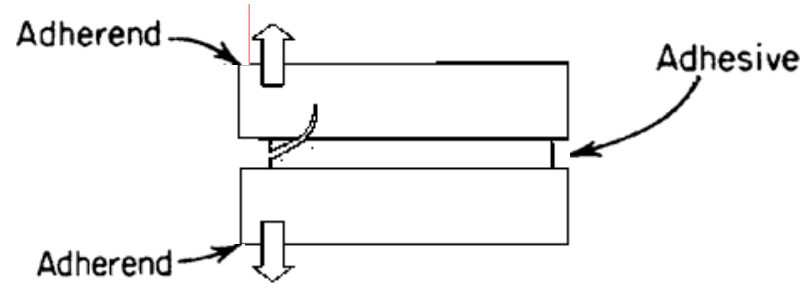

Figure 1.9 Adherend failure mode [36].

In many cases, both types occur concurrently with varying levels of interaction. It has been observed in simple tension tests of uniform rectangular cross section specimen (Edge Delamination tests) that delaminations initiate along the load free edges and propagate normal to the load direction. Transverse matrix cracks running parallel to the fibers have also been observed in off axis plies such as $90^{\circ}$ plies. Such transverse cracks terminate where the ply orientation changes. Delaminations can also originate at the interfaces where transverse cracks terminate. These delaminations, called transverse crack tip delaminations or local delaminations grow normal to the transverse crack from which they originate. In the case of $90^{\circ}$ plies, the growth direction is parallel to the load [34]. 
The growth process of edge delaminations and local delaminations is often modeled using a fracture mechanics approach leading to the calculation of a strain energy release rate. This is because the strain energy release rate can correlate delamination behavior from different loading conditions and can account for geometric dependencies. The strain energy release rate associated with a particular growth configuration is a measure of the driving force behind that failure mode. In combination with appropriate failure criteria, the strain energy release rate provides a means of predicting the failure loads of the structure. Delaminations near free edges, holes, ply drops, and notches have been noticed in laminated composites in service. In practical composite structures, delamination is a mixed mode fracture process which includes Mode I or the opening mode, Mode II or the shearing mode, and Mode III or the tearing mode.

The growth process of edge delaminations and local delamination is often modeled by a fracture mechanics approach leading to the calculation of a strain energy release rate (SERR). This is because the strain energy release rate can account for different geometric dependencies and loading conditions.

Several methods are available in the literature for analyzing edge delaminations. These include finite element modeling, complex variable stress potential approach [34, 35, 37], simple classical laminate theory based techniques and higher order laminate theory including shear deformation and finite element models provide accurate solutions but involve intensive computational effort. Classical laminate theory (CLT) provides simple closed form solutions and is thus well suited for preliminary design evaluation. However, CLT provides only the total energy release rate, and thus, in a mixed mode situation, there is insufficient information to completely assess the delamination growth tendency. A higher order laminate theory including 
shear deformations has the ability to provide the individual contributions of the three fracture modes while retaining the simplicity of a closed form solution [33].

\subsubsection{Analytical Approach to Evaluate Failure modes}

It is well known that analytical analysis is an important means to identify effective parameter and closed form approach. Thus, considerable efforts have been done to theoretical and analytical approach of adhesive bonded joints. Stress analysis using a shear lag model pioneered by Volkersen (1938). Considering adherend bending and adherends' large deflection as well as adhesive peeling effects Goland and Reissener (1944) had a significant contribution. Their work has been widely used and evaluated experimentally and analytically by many investigators. One of the most noticeable works is the investigation of Hart-Smith (1973), who considered coupling effect of adhesive strains with is overall deformation of the SLJ. Oplinger (1994) improved the Hart-Smith (1973) model by considering the overlap large deflection coupling with adhesive shear stress. Harris and Adams (1984) investigated the strength of bonded single lap joints using nonlinear finite element. They indicated a small discrepancy in adhesive shear stress distribution using classical closed form solutions and the finite element analysis, and large differences in the peel stress as well as edge moment. Recently Luo and Tong (2007) presented accurate closed form solutions that predict edge moment and adhesive stress. Also Yang et al. [38, 39] investigated strength analysis of SLJ using energy approach for thin and thick adhesive bondlines.

Studies of adhesive-bonded joints also can be found in the extensive reviews given by Kutscha [40], Kutscha and Hofer [41], Matthews et al. [42], and Vinson [43]. Yang and Pang [44] derived an analytical model that provided the stress distributions of adhesive-bonded singlelap composite joints subjected to axial tension. Huang et al. [45] and Yang et al. [46] also 
derived an elastic-plastic model for adhesive-bonded single-lap composite joints. Important capabilities included in their approaches were the asymmetry of the adherend laminates as well as the effects due to transverse shear deformation.

In most studies, fracture failure analyses using finite element approaches to predict failure load has been investigated [40, 47, 48]. Adhesive and cohesive failure analyses and also fracture mechanics of lap joints have been vastly investigated [38-49]. Nevertheless, out-of plane failure analyses of adhesive-bonded joints have not been inquired sufficiently.

Several methods have been used for the delamination analysis of laminated composites in mixed mode situation. Most of them are based upon finite element simulations [49-51]. An analytical solution were purposed by Wang [53] for the edge delamination analysis in a $[\theta,-\theta]_{\mathrm{s}}$ angle ply laminate. The development is based on complex-variable stress potentials, and a boundary-collocation method is used to determine the laminate elasticity solution in explicit

form. A ply-level analysis has been developed by Valisetty and Rehfield [54] for beams and plates.

The interlaminar fracture in composites using sublaminate approach has been widely studied by Armanios et al. [34,35,37] and Rehfield et al. [55], however, such simplifications as geometry symmetry and balance lay up sequence related to the case study assumed.

\subsubsection{Finite Element Approach to Evaluate Failure modes}

The finite element method (FEM) is playing a significant role in the structural analysis and has been widely used to study the adhesive-bonded joint. Wang et al. [56] applied the virtual crack closure technique (VCCT) to calculate strain energy release rate of cracked composite panels with nonlinear deformation. This method is used in conjunction with FEM and requires only one finite element execution. Wei et al. [57] presented an improved VCCT to determine the 
energy release rate with three step analysis: (a) the displacement of crack tip was propagated for one element and (b) constraint were applied to force the opened crack tip close, and (c) the reaction forces were multiplied by the relative displacement to obtain the energy release rate.

Yang and Guan [46] developed finite element models to estimate the $J$-integral of adhesive bonded single lap joint using ABAQUS [57] commercial package. ASTM D5656 and ASTM D3165 specimen have been used for their finite element model. The critical location near notch and holes where stress concentration occurs during the loading process has been observed. Compared with experimental data, a fair prediction of failure loads can be achieved using the critical $J$ criterion.

The FEM has been widely employed to investigate stresses and for the bond lines. Chan et al. (1970) and Hellen (1975) are among those who have extended the technique to apply the principal of fracture mechanics to cohesive fractures. Anderson et al. (1973) and Henshell and Shew (1975) have produced the characteristic of $r^{-1 / 2}$ singularity of a cracked configuration by distorting the four elements adjacent to the crack tip and successfully have applied it to fracture mechanics problems.

\subsection{ASTM D3165 Standard Specimen}

Adhesive-bonded single-lap composite joint was considered in the current study. ASTM D3165 [59] specimen shown in Figure.1.9, was followed to perform the stress analysis and to estimate energy release rate. ASTM D3165 "The Standard Test Method for Strength Properties of Adhesive in Shear by Tension Loading of Single-Lap Joint Laminated Assemblies" is intended for determining the comparative shear strength of adhesives single-lap joint. Because of the rotation of the test area, the shear and peel effects are coupled together to determine the 
failure mode. According to reference [48], a fracture failure criterion based on $J$-integral is applicable to ASTM D3165.
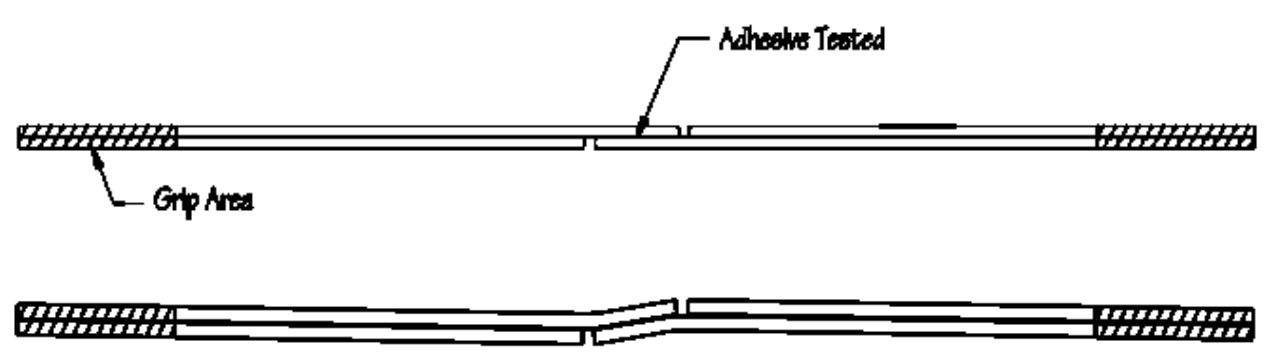

Figure 1.10 ASTM D3165 specimen configuration and deformation [32].

In previous works, FEM and analytical model to estimate strain energy release rate of ASTM D3165 have been conducted by Yang et al. to predicate adhesive failure analysis of the joint; however, current study has been focused on estimation of strain energy release rate prediction of ASTM D3165. 


\section{CHAPTER 2}

\section{MODEL DEVELOPMENT}

Details of the analytical method for determining the strain energy release rate of adhesive-bonded single-lap composite joints with a prescribed interlaminar crack is based on the laminated plate theory version of Irwin's virtual crack method [60]. The SERR is derived in terms of the forces and moment at the crack-tip, $N_{C}, Q_{C}$, and $M_{C}$. These forces and moment at the crack tip are determined from the linear elastic shear and peel stress distributions at the firstply adherend interface within the overlap area. Therefore, a description of the stress state in the pre- and post-propagation specimen geometry is required before an estimate of the strain energy release rate can be obtained. A summary of the methodology used to derive the equations for determining the required stress and displacement fields in an adhesive-bonded joint is presented in this section.

An adhesive-bonded single-lap joint with the standard geometry of an ASTM D3165 specimen and an applied tensile load $P$ per unit width is shown in Fig. 2.1. Here, the joint is

divided into six regions for convenience in the model development, where Regions 1, 4, and 6 consist of two adherends and a thin adhesive layer, Regions 2 and 5 represent two notches, and Region 3 is also assumed to be due to first-ply failure of the laminate in the overlap area and its corresponding geometry discontinuity. Region 4 is the bonded-joint overlap area where the applied mechanical loads are transferred from one adherend to the other and is also the area on which joint strength is typically based. 


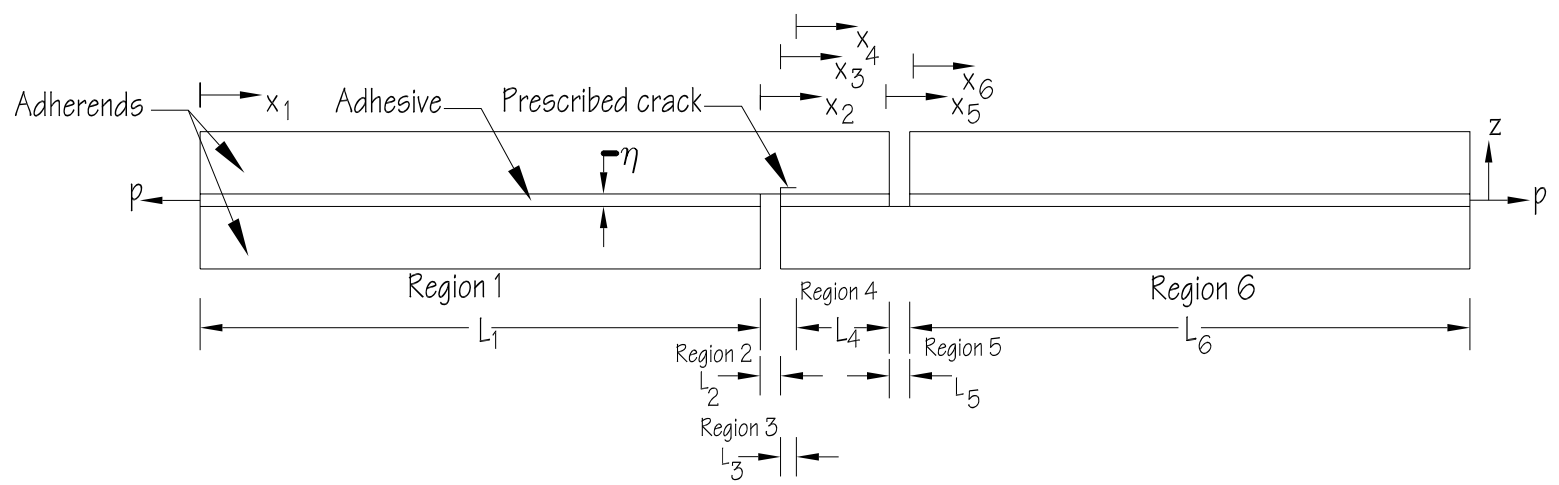

Figure 2.1 ASTM D3165 specimen geometry [59].

The step-by-step solution procedure can be summarized as follows:

1. Divide the model into adherend portions according to the ASTM D3165 specimen geometry, and derive the kinematics relations for each adherend portion.

2. Write force and moment equilibriums for each adherend portion with respect to sign convention.

3. Derive equations for the adhesive and interlaminar stresses using the kinematics of adherends.

4. Specify boundary conditions according to the loading status and displacement constraints.

5. Find the equivalent crack-tip forces and moment, and propagate the crack to find displacement distributions.

6. Apply the VCCT formulation to calculate the SERR.

\subsection{Adherend Formulation}

The specimen is discretized into twelve adherend portions from left to right, as shown in Fig. 2.2. The general formulas for the adherend portions are the same for all adherend portions, except for Adherend Portions 5 and 8. The displacement fields of the adherend are described by the laminated anisotropic plate theory. 


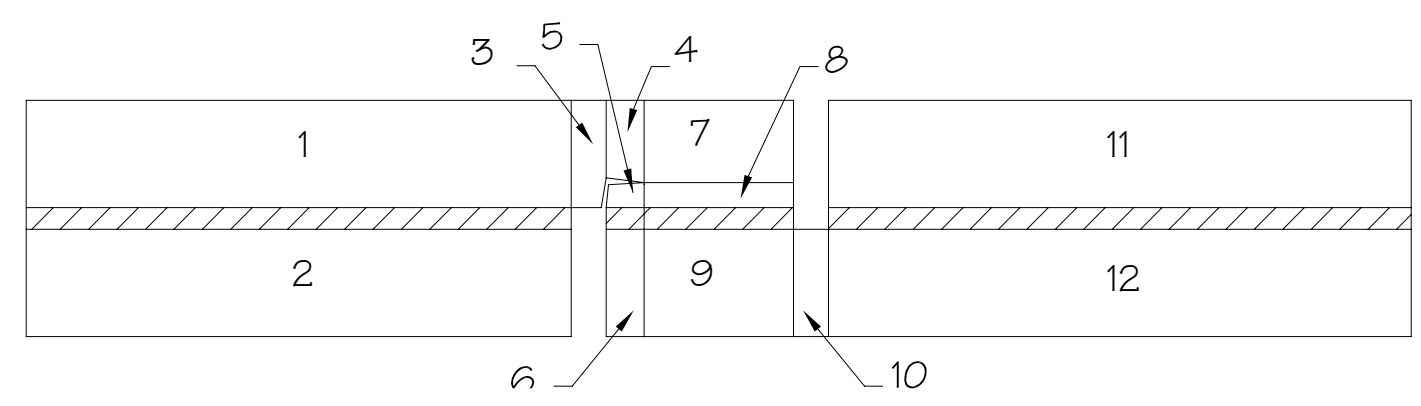

Figure 2.2 Discretized model with 12 adherend portions.

\subsubsection{Adherend Portions 1-4, 6, 7, and 9-12}

Based on the first-order laminated plate theory, the displacement fields for the Adherend Portions $1-4,6,7$, and $9-12$ can be written as

$$
\begin{gathered}
u=u^{o}(x)+z \psi(x) \\
w=w(x)
\end{gathered}
$$

where the superscript " $o$ " represents the mid-plane displacement, $z$ is measured from the midplane of each adherend portion, and $\psi$ is the corresponding bending slope. Considering the given displacement functions and the strain-displacement relations yields the normal strain $\varepsilon_{x}$ and shear strain $\gamma_{x y}$ for each adherend portion as

$$
\begin{gathered}
\varepsilon_{x}=\frac{d u}{d x}=\frac{d u^{o}(x)}{d x}+z \frac{d \psi(x)}{d x} \\
\gamma_{x y}=\frac{d w}{d x}+\frac{d u}{d z}=\frac{d w(x)}{d x}+\psi(x)
\end{gathered}
$$

Therefore, based on the classical laminate theory (CLT), the relationships among stress resultants, strain, and bending slope can be formulated. Furthermore, using the extensional stiffness $[A]$, the coupling stiffness $[B]$, and the bending stiffness $[D]$ for orthotropic laminates, the normal stress resultant $N_{x}$, bending moment for unit width $M_{y}$, and transverse shear stress resultant $Q_{z}$ can be obtained as 


$$
\begin{aligned}
& N_{x}=A_{11} \frac{d u^{o}(x)}{d x}+B_{11} \frac{d \psi(x)}{d x} \\
& M_{y}=B_{11} \frac{d u^{o}(x)}{d x}+D_{11} \frac{d \psi(x)}{d x} \\
& Q_{z}=k_{s} A_{55}\left[\psi(x)+\frac{d w(x)}{d x}\right]
\end{aligned}
$$

where $k_{s}$ is the shear correction factor, and $A_{i j}, B_{i j}$, and $D_{i j}$ terms are taken from the common extensional, bending, and extensional-bending coupling stiffness matrices from the laminated plate theory as

$$
\begin{gathered}
\left(A_{11}, B_{11}, D_{11}\right)=\int_{-h / 2}^{h / 2} Q_{11}^{(i)}\left[1, \quad z, z^{2}\right] d z \\
A_{55}=\int_{-h / 2}^{h / 2} Q_{55}^{(i)} d z
\end{gathered}
$$

The $Q_{11}{ }^{(i)}$ and $Q_{55}{ }^{(i)}$ represent the normal and transverse shear stiffness, respectively, of the $i^{\text {th }}$ ply.

\subsubsection{Adherend Portion 5}

Due to the small length-to-thickness ratio of Adherend Portion 5, which is a single ply, displacement distributions $u$ and $w$ in the $x$ - and $z$-directions, respectively, are assumed to follow the "semi-elastic medium" approach. The normal and shear stress resultants $N_{5 x}$ and $Q_{5 z}$, and the bending moment $M_{5 y}$ per unit width are related to the strains within the adherend portion and the constitutive relations of the adhesive material. Because Adherend Portion 5 is only one ply and very thin, the normal strain and slope at the mid-plane, $d u_{5}{ }^{o} / d x$ and $d w_{5}{ }^{o} / d x$, are used to determine $N_{5 x}$ and $Q_{5 z}$. Also, because of the small thickness, $M_{5 y}$ is assumed to be negligible.

$$
N_{5 x}=\int_{-h_{2} / 2}^{h_{2} / 2} Q_{11} \frac{d u_{5}^{o}(x)}{d x} d z
$$




$$
\begin{gathered}
M_{5 y}=\int_{-h_{2} / 2}^{h_{2} / 2} Q_{11} \frac{d u_{5}^{o}(x)}{d x} z d z \approx 0 \\
Q_{5 z}=\int_{-h_{2} / 2}^{h_{2} / 2} k_{s} Q_{55}\left[\frac{d u_{5}^{o}(x)}{d z}+\frac{d w_{5}^{o}(x)}{d x}\right] d z
\end{gathered}
$$

In order to correlate the shear and peel stresses at the adherend/adhesive interface at the bottom of Adherend Portion 5, the displacements at the mid-plane and bottom surface of Adherend Portion 5 are used, assuming that $\sigma_{z}$ and $\tau_{x z}$ are uniform within the lower half of Adherend Portion 5. Therefore, as shown in Fig. 2.3, the shear stress and peel stresses $\tau_{a}{ }^{*}$ and $q_{a}{ }^{*}$ are the same as $\sigma_{z}$ and $\tau_{x z}$ within the lower half of Adherend Portion 5 and can be represented in terms of the mid-plane displacements $u_{5}{ }^{\circ}$ and $w_{5}{ }^{\circ}$ and the bottom surface displacements $u_{5}{ }^{*}$ and $w_{5}{ }^{*}$ as

$$
\begin{gathered}
\tau_{a}^{*}=\left.\tau_{x z}\right|_{z=-h_{2} / 2}=-G_{x z}\left[\frac{2}{h_{2}}\left(u_{5}^{o}-u_{5}^{*}\right)+\frac{d w_{5}^{o}}{d x}\right] \\
q_{a}^{*}=\left.\sigma_{z}\right|_{z=-h_{2} / 2}=\left(\frac{v_{x z}+v_{x y} v_{y z}}{E_{x} E_{y} \Delta}\right) \frac{d u_{5}^{o}}{d x}+2\left(\frac{1-v_{x y} v_{y x}}{E_{x} E_{y} \Delta}\right) \frac{\left(w_{5}^{o}-w_{5}^{*}\right)}{h_{2}}
\end{gathered}
$$

where $h_{2}$ is the thickness of one single ply, $v_{x y}$ and $v_{y x}$ are Poisson's ratios in the $x-y$ plane, $v_{x z}$ is Poisson's ratio in the $x-z$ plane, $v_{y z}$ is Poisson's ratio in the $y-z$ plane, and $E_{x}, E_{y}$, and $G_{x z}$ are the moduli of elasticity in the $x$ - and $y$-directions and shear modulus in the $x$-z plane, respectively. $\Delta$ can be given as

$$
\Delta=\frac{1-v_{x y} v_{y x}-v_{y z} v_{z y}-v_{z x} v_{x z}-2 v_{x y} v_{y z} v_{z x}}{E_{x} E_{y} E_{z}}
$$

where $v_{z y}$ is Poisson's ratio in the $z-y$ plane, $v_{z x}$ is Poisson's ratio in the $x-z$ plane, and $E_{z}$ is the modulus of elasticity in the $z$-direction. 


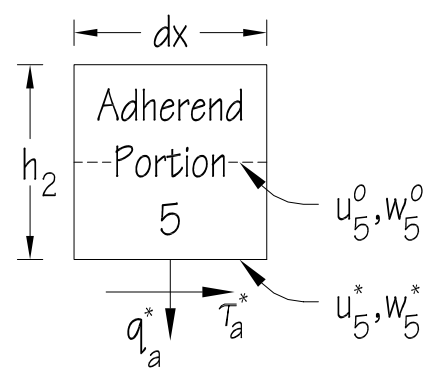

Figure 2.3 Free-body diagram of Adherend Portion 5.

\subsubsection{Adherend Portion 8}

Similar to Adherend Portion 5, Adherend Portion 8 is also a single ply. The "semi-elastic medium" approach is considered for Adherend Portion 8 as well. The normal and shear stress resultant and bending moment per unit width can be related to the displacement fields as specified in Eqs. (2.10)-(2.12). The shear and peel stresses at the bottom surface of Adherend Portion 8 are formulated using the same methodology used for Adherend Portion 5, Eqs. (2.13) and (2.14), in terms of the mid-plane displacements $u_{8}{ }^{\circ}$ and $w_{8}{ }^{\circ}$ and the bottom surface displacements $u_{8}{ }^{*}$ and $w_{8}{ }^{*}$.

The shear and peel stresses $\tau_{i}$ and $\sigma_{i}$ at the upper surface of Adherend Portion 8, as shown in Fig. 2.4, which are the interlaminar stresses between Adherend Portions 7 and 8, are to be used for the equivalent crack-tip forces calculation and, later on, for the strain energy release rate determination. Assuming uniform $\sigma_{z}$ and $\tau_{x z}$ within the upper half of Adherend Portion 8 and a perfect bond between Adherend Portions 7 and 8, based on the kinematics and constitutive relations, $\tau_{i}$ and $\sigma_{i}$ are related to the displacement functions of Adherend Portions 7 and 8 as

$$
\begin{gathered}
q_{i}=\left(\frac{v_{x z}+v_{x y} v_{y z}}{E_{x} E_{y} \Delta}\right) \frac{1}{2} \frac{d}{d x}\left(u_{7}^{o}-\frac{h_{1}}{2} \psi_{7}+u_{8}^{o}\right)+\left(\frac{1-v_{x y} v_{y x}}{E_{x} E_{y} \Delta}\right)\left[\frac{2}{h_{2}}\left(u_{7}^{o}-\frac{h_{1}}{2} \psi_{7}-u_{8}^{o}\right)+\frac{d w_{8}^{o}}{d x}\right] \\
\tau_{i}=-G_{x z}\left[\frac{2}{h_{2}}\left(u_{7}^{o}-\frac{h_{1}}{2} \psi_{7}-u_{8}^{o}\right)+\frac{d w_{8}^{o}}{d x}\right]
\end{gathered}
$$




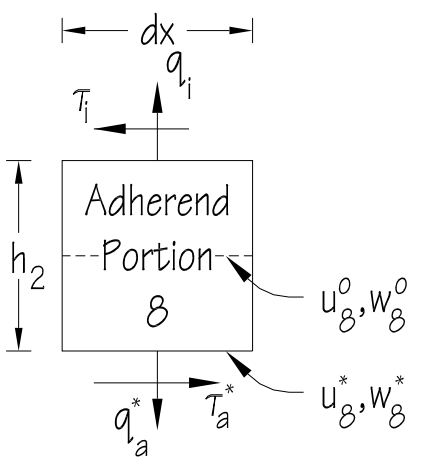

Figure 2.4 Free-body diagram of adherend Portion 8 .

The shear and peel stresses $\tau_{a}{ }^{*}$ and $q_{a}{ }^{*}$ at the bottom surface of Adherend portion 8 are derived in the same way as those in Adherend portion 5, and $u_{8}{ }^{*}$ and $w_{8}{ }^{*}$ shown in Fig. 2.4 will be solved later by equating the corresponding adhesive stress distributions given by the kinematics of Adherend Portions 8 and 9.

\subsection{Adhesive Formulation}

The adhesive is assumed to behave as an elastic-isotropic material. Using the kinematics of the adherends and assuming a perfect bond between the adhesive and the adherend surfaces, the adhesive strains are related to the displacements of the surfaces of the adherend portions adjacent to the adhesive. According to the discretized model shown in Fig. 2.2, an adhesive bondline presents in Regions 1, 3, 4, and 6. The general formulas for Regions 1 and 6 are the same where the upper and lower adherends contain only one adherend portion. In Regions 3 and 4, however, the adherend above the adhesive is modeled as two adherend portions. Therefore, the adhesive formulation in Regions 3 and 4 are different than those in Regions 1 and 6.

\subsubsection{Adhesive Formulation in Regions 1 and 6}

In terms of the displacement field of the upper and lower adherends, the adhesive strains in Regions 1 and 6, with traditional sign conventions, can be written as 


$$
\begin{gathered}
\gamma_{x z}=\frac{1}{\eta}\left[\left(u^{o U}-u^{o L}\right)-\left(\frac{h^{U}}{2} \psi^{U}+\frac{h^{L}}{2} \psi^{L}\right)\right]+\frac{1}{2}\left(\frac{d w^{L}}{d x}+\frac{d w^{U}}{d x}\right) \\
\varepsilon_{x}=\frac{1}{2} \frac{d}{d x}\left[\left(u^{o L}+u^{o U}\right)+\left(\frac{h^{L}}{2} \psi^{L}-\frac{h^{U}}{2} \psi^{U}\right)\right] \\
\varepsilon_{z}=\frac{1}{\eta}\left(w^{U}-w^{L}\right)
\end{gathered}
$$

where $\eta$ is the adhesive thickness, and $h^{U}$ and $h^{L}$ are the thickness of the upper and lower adherends, respectively. Assuming a plane-strain condition, adhesive shear stress $\tau_{a}$ and peel stress $q_{a}$ can be obtained as

$$
\begin{gathered}
q_{a}=\frac{E_{a}}{\left(1+v_{a}\right)\left(1-2 v_{a}\right)}\left[v \varepsilon_{x}+\left(1-v_{a}\right) \varepsilon_{z}\right] \\
\tau_{a}=-G_{a} \gamma_{x z}
\end{gathered}
$$

where the sign conventions are shown in Fig. $2.5, E_{a}$ is the Young's modulus, $v_{a}$ is the Poisson's ratio, and $G_{a}$ is the shear modulus of the adhesive.

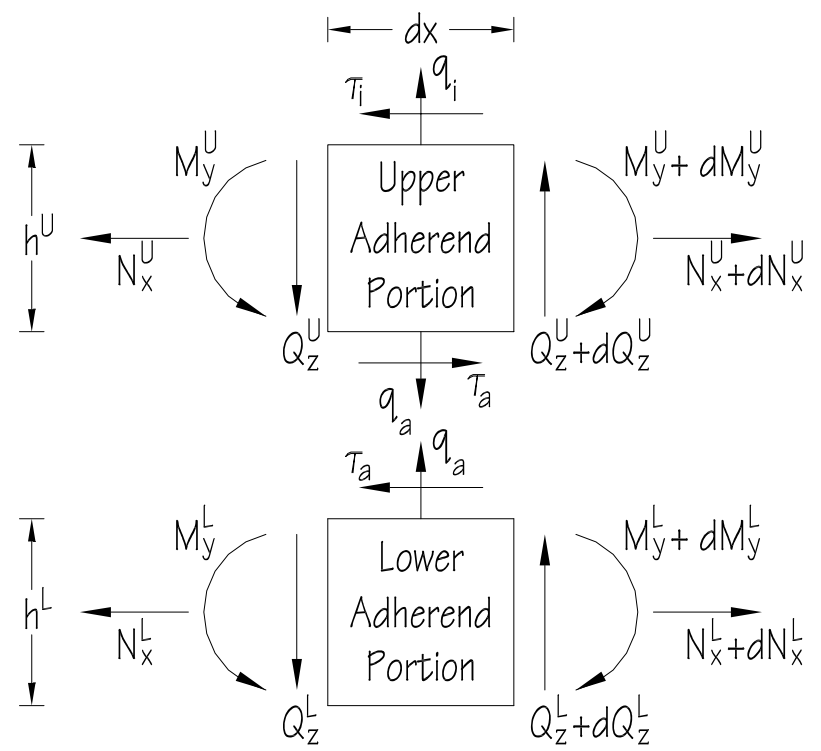

Figure 2.5 General free-body diagram and sign convention. 


\subsubsection{Adhesive Formulation in Regions 3 and 4}

In Regions 3 and 4, the adherend portions above the adhesive, namely Adherend Portion 5 in Region 3 and Adherend Portion 8 in Region 4, are a single ply. While the adherend portion above the adhesive is modeled using the "semi-elastic media" approach, the adherend portion below the adhesive is modeled using the first-order laminated plate theory. In terms of the displacement fields of the adherend portions above and below the adhesive, the adhesive strains for Regions 3 and 4 with the traditional sign conventions can be written as

$$
\begin{gathered}
\gamma_{x z}=\frac{1}{\eta}\left(u^{*}-u^{o L}-\frac{h^{L}}{2} \psi^{L}\right)+\frac{1}{2}\left(\frac{d w^{o}}{d x}+\frac{d w^{L}}{d x}\right) \\
\varepsilon_{x}=\frac{1}{2}\left(\frac{d u^{*}}{d x}+\frac{d\left(u^{o L}+\frac{h^{L}}{2} \psi^{L}\right)}{d x}\right) \\
\varepsilon_{z}=\frac{1}{\eta}\left(w^{*}-w^{L}\right)
\end{gathered}
$$

where $u^{*}$ and $w^{*}$ are the displacements in the $x$ - and $z$-directions, respectively, at the bottom surface of the adherend portion immediately above the adhesive, as shown in Figs. 2.3 and 2.4. The adhesive shear stress $\tau_{a}$ and peel stresses $q_{a}$ can be obtained by substituting Eqs. (2.23)(2.25) into Eqs. (2.21) and (2.22).

\subsection{Adherend Equilibrium Equations}

In order to establish the equations of equilibrium for each adherend portion, a free-body diagram of a differential element from the overlap regions is illustrated in Fig. 2.5. The upper adherend portion shown in the figure is the adherend portion immediately above the adhesive and represents Adherend Portions 1, 5, 8, and 12 in Regions 1, 3, 4, and 6, respectively. The lower adherend portion in the figure is the lower adherend under the adhesive in each region. 
The general equations for force and moment equilibrium of the adherend portion above the adhesive are given as

$$
\begin{gathered}
\frac{d N_{x}^{U}}{d x}=\tau_{i}-\tau_{a} \\
\frac{d M_{y}^{U}}{d x}=Q_{z}^{U}+\frac{h^{U}}{2}\left(\tau_{a}+\tau_{i}\right) \\
\frac{d Q_{z}^{U}}{d x}=q_{a}-q_{i}
\end{gathered}
$$

As mentioned previously, $\tau_{a}$ and $q_{a}$ are the shear and peel stresses of the adhesive, whereas $\tau_{i}$ and $q_{i}$ are the interlaminar shear and peel stresses, respectively, and $h^{U}$ is the thickness of the upper adherend portion. It should be noted that $\tau_{i}$ and $q_{i}$ do not exist in Regions 1 and 6 because the upper adherend portions in these two regions are modeled as one piece, while the upper adherend portions in Region 3 and 4 are one ply, and $\tau_{i}$ and $q_{i}$ are the interlaminar stresses, as shown in Figs. 2.3 and 2.4.

Three equilibrium equations can also be obtained for the adherend portion below the adhesive in a similar manner, but without any stresses at the bottom surface, as

$$
\begin{gathered}
\frac{d N_{x}^{L}}{d x}=\tau_{a} \\
\frac{d M_{y}^{L}}{d x}=Q_{z}^{L}+\frac{h^{L}}{2} \tau_{a} \\
\frac{d Q_{z}^{L}}{d x}=-q_{a}
\end{gathered}
$$

where $h^{L}$ is the thickness of the adherend portion below the adhesive. 
Based on the general equilibrium equations for the adherend portions above and below the adhesive, equations of equilibrium for each adherend portion can be written and are described in detail below.

\subsubsection{Region 1- Adherend Portions 1 and 2}

From the free-body diagram in Fig. 2.5, it can be observed that $\tau_{i}=0$ and $q_{i}=0$, because the top surface of adherend Portion 1 is a free-traction surface. Hence, Eqs. (2.26)-(2.31) can be rewritten as

$$
\begin{gathered}
\frac{d N_{1 x}}{d x}=-\tau_{a} \\
\frac{d M_{1 y}}{d x}=Q_{1 z}+\frac{h}{2} \tau_{a} \\
\frac{d Q_{1 z}}{d x}=q_{a} \\
\frac{d N_{2 x}}{d x}=\tau_{a} \\
\frac{d M_{2 y}}{d x}=Q_{2 z}+\frac{h}{2} \tau_{a} \\
\frac{d Q_{2 z}}{d x}=-q_{a}
\end{gathered}
$$

By substituting the stress resultants from Eqs. (2.5)-(2.7) and the adhesive stresses $\tau_{a}$ and $q_{a}$ from Eqs. (2.21) and (2.22) and Eqs. (2.18)-(2.20) into Eqs. (2.32)-(2.37), six coupled secondorder ordinary differential equations in terms of $u_{1}{ }^{\mathrm{o}}, u_{2}{ }^{\mathrm{o}}, \psi_{1}, \psi_{2}, w_{1}$, and $w_{2}$ are obtained. 


\subsubsection{Region 2-Adherend Portion 3}

Region 2 represents a notch in the overall specimen geometry. Because of the interlaminar failure assumed between adherend Portions 4 and 5, where the first ply is supposed to continue from the lower right end of adherend Portion 3 and form adherend portion 5 , a crack is initiated between adherend Portions 3 and 5, as shown in Fig. 2.6, as the "free surface." Because of the "free surface" at the lower right end of adherend Portion 3, the effective thickness and the tensile, bending, and shear stiffness of adherend Portion 3 are different from its left end to its right end. Based on the free-body diagram shown in Fig. 2.6, equations of equilibrium can be written as

$$
\begin{gathered}
N_{3 x}^{L}=N_{3 x}^{R} \\
Q_{3 z}^{L}=Q_{3 z}^{R} \\
M_{3 y}^{R}=M_{3 y}^{L}-N_{3 x}^{L} \frac{h_{2}}{2}+Q_{3 z}^{L} L_{2}
\end{gathered}
$$

where superscript " $L$ " and " $R$ " refer to the left and right ends of adherend Portion 3 , respectively, $h_{2}$ is the thickness of a single ply, and $L_{2}$ is the entire length of adherend Portion 3.

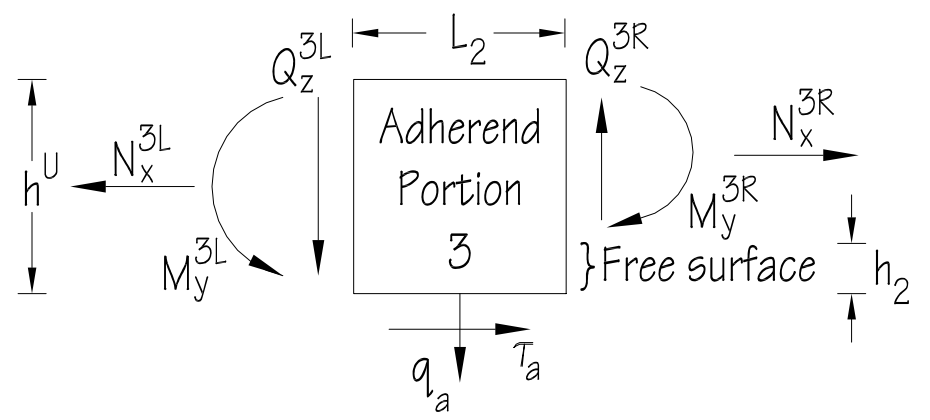

Figure 2.6 Free-body diagram of Adherend Portion 3.

In order to obtain $u_{3}{ }^{o}, \psi_{3}$, and $w_{3}$ at the right end of adherend Portion 3, the following equations are used, assuming a small change in their derivatives: 


$$
\begin{aligned}
& \left.u_{3}^{o}\right|_{x_{2}=L_{2}}=\left.u_{3}^{o}\right|_{x_{2}=0}+\frac{L_{2}}{2}\left(\left.\frac{d u_{3}^{o}}{d x}\right|_{x_{2}=0}+\left.\frac{d u_{3}^{o}}{d x}\right|_{x_{2}=L_{2}}\right) \\
& \left.\psi_{3}\right|_{x_{2}=L_{2}}=\left.\psi_{3}\right|_{x_{2}=0}+\frac{L_{2}}{2}\left(\left.\frac{d \psi_{3}}{d x}\right|_{x_{2}=0}+\left.\frac{d \psi_{3}}{d x}\right|_{x_{2}=L_{2}}\right) \\
& \left.w_{3}\right|_{x_{2}=L_{2}}=\left.w_{3}\right|_{x_{2}=0}+\frac{L_{2}}{2}\left(\left.\frac{d w_{3}}{d x}\right|_{x_{2}=0}+\left.\frac{d w_{3}}{d x}\right|_{x_{2}=L_{2}}\right)
\end{aligned}
$$

where the first-order derivatives of $u_{3}^{o}, \psi_{3}$, and $w_{3}$ are at the right end, where $x_{2}=L_{2}$ can be determined by the following equations, which are based on equilibrium equations Eqs. (2.38)(2.40). In the following equations, Eqs. (2.44)-(2.46), the values of $u_{3}^{o}, \psi_{3}, w_{3}$, and their derivatives at the left end, where $x_{2}=0$, are obtained from the right end of Adherend Portion 1

using the continuity condition. It should be noted that the stiffness $A_{11}, B_{11}, D_{11}$, and $A_{55}$ have different values at the left and right ends due to delamination of the first ply at the right end.

$$
\begin{gathered}
\left.\left(A_{11} \frac{d u_{3}^{o}}{d x}\right)\right|_{x_{2}=0}+\left.\left(B_{11} \frac{d \psi_{3}}{d x}\right)\right|_{x_{2}=0}=\left.\left(A_{11} \frac{d u_{3}^{o}}{d x}\right)\right|_{x_{2}=L_{2}}+\left.\left(B_{11} \frac{d \psi_{3}}{d x}\right)\right|_{x_{2}=L_{2}} \\
\\
{\left.\left[k_{s} A_{55}\left(\psi_{3}+\frac{d w_{3}}{d x}\right)\right]\right|_{x_{2}=0}=\left.\left[k_{s} A_{55}\left(\psi_{3}+\frac{d w_{3}}{d x}\right)\right]\right|_{x_{2}=L_{2}}} \\
\left.\left(B_{11} \frac{d u_{3}^{o}}{d x}\right)\right|_{x_{2}=L_{2}}+\left.\left(D_{11} \frac{d \psi_{3}}{d x}\right)\right|_{x_{2}=L_{2}}=\left.\left(B_{11} \frac{d u_{3}^{o}}{d x}\right)\right|_{x_{2}=0}+\left.\left(D_{11} \frac{d \psi_{3}}{d x}\right)\right|_{x_{2}=0} \\
-\frac{h_{2}}{2}\left[\left.\left(A_{11} \frac{d u_{3}^{o}}{d x}\right)\right|_{x_{2}=0}+\left.\left(B_{11} \frac{d \psi_{3}}{d x}\right)\right|_{x_{2}=0}\right]+L_{2}\left[k_{s} A_{55}\left(\psi_{3}+\frac{d w_{3}}{d x}\right)\right] \mid
\end{gathered}
$$

\subsubsection{Region 3-Adherend Portion 4}

Due to first-ply failure at the bottom surface and the free-traction surface at the top, equations of equilibrium of adherend Portion 4 can be written as 


$$
\begin{aligned}
\frac{d N_{4 x}}{d x} & =0 \\
\frac{d M_{4 y}}{d x} & =Q_{4 z} \\
\frac{Q_{4 z}}{d x} & =0
\end{aligned}
$$

Substituting the stress resultants as functions $u_{4}{ }^{\circ}, \psi_{4}$, and $w_{4}$ yields three coupled second-order ordinary differential equations in terms of $u_{4}{ }^{\circ}, \psi_{4}$, and $w_{4}$.

\subsubsection{Region 3-Adherend Portions 5 and 6}

As previously noted, Adherend Portion 5 contains a single ply and is separated from Adherend Portion 4 due to the prescribed interlaminar crack. The equations of equilibrium of Adherend Portions 5 and 6 are similar to those for Adherend Portions 1 and 2 but without considering the bending moment in Adherend Portion 5, as previously mentioned.

$$
\begin{gathered}
\frac{d N_{5 x}}{d x}=-\tau_{a} \\
\frac{d Q_{5 z}}{d x}=q_{a} \\
\frac{d N_{6 x}}{d x}=\tau_{a} \\
\frac{d M_{6 y}}{d x}=Q_{6 z}+\frac{h}{2} \tau_{a} \\
\frac{d Q_{6 z}}{d x}=-q_{a}
\end{gathered}
$$

Plugging in the stress resultants from Eqs. (2.10) and (2.12) for $N_{5 x}$ and $Q_{5 z}$, Eqs. (2.5)(2.7) for $N_{6 x}, M_{6 y}$, and $Q_{6 z}$, five coupled second-order ordinary differential equations $u_{5}^{o}, w_{5}^{o}, u_{6}^{o}$, 
$w_{6}$, and $\psi_{6}$ are obtained. Thus, $u_{5}{ }^{*}$ and $w_{5}{ }^{*}$ can be solved in terms of all other variables by equating the shear and peel stresses at the bottom surface of Adherend Portion 5, as specified in Eqs. (2.13) and (2.14), with the adhesive shear and peel stresses using adhesive strains in Eqs. $(2.23)-(2.25)$ as

$$
\begin{aligned}
\tau_{a}^{*} & =\tau_{a} \\
q_{a}^{*} & =q_{a}
\end{aligned}
$$

\subsubsection{Region 4-Adherend Portions 7, 8, and 9}

A similar approach as that used for Region 3 for Adherend Portions 5 and 6 can be applied to Region 4, with an additional adherend portion at the top and at the interlaminar stresses. Eight equations can be written based on normal stress resultants, bending moment, and shear stress resultants as

$$
\begin{gathered}
\frac{d N_{7 x}}{d x}=-\tau_{i} \\
\frac{d M_{7 y}}{d x}=Q_{7 z}+\frac{h_{1}}{2} \tau_{i} \\
\frac{d Q_{7 z}}{d x}=q_{i} \\
\frac{d N_{8 x}}{d x}=\tau_{a}-\tau_{i} \\
\frac{d Q_{8 z}}{d x}=q_{i}-q_{a} \\
\frac{d N_{9 x}}{d x}=\tau_{a} \\
\frac{d M_{9 y}}{d x}=Q_{9 z}+\frac{h}{2} \tau_{a}
\end{gathered}
$$




$$
\frac{d Q_{9 z}}{d x}=-q_{a}
$$

where $h_{1}$ and $h$ are thicknesses of Adherend Portion 7 and Adherend Portion 9, respectively. The interlaminar shear and peel stresses $\tau_{i}$ and $q_{i}$ between Adherend Portions 7 and 8 are in terms of displacement fields of Adherend Portions 7 and 8, as shown in Eqs. (2.16) and (2.17).

Using the same methodology as used in Region 3, Adherend Portions 5 and $6 u_{8}{ }^{*}$ and $w_{8}{ }^{*}$ can be determined by equating $\tau_{a}{ }^{*}$ and $q_{a}{ }^{*}$ with $\tau_{a}$ and $q_{a}$.

\subsection{Region 5-Adherend Portion 10}

This region represents a notch in the model. Equations of equilibrium are the same as those given for Adherend Portion 4, while stiffness matrices are different.

\subsubsection{Region 6-Adherend Portions 11 and 12}

Due to the similarities between Region 1 and Region 6, the same equations of equilibrium can be driven for Region 6 with new variables.

The overall system of governing equations, including all six regions, contains 31 secondorder ordinary differential equations with 31 unknown variables. A total of 62 boundary conditions are obtained at the two ends of each region, based on either continuity or applied

force conditions. The symbolic solver Maple 9.52 [61] was used to solve the system of equations and obtain the displacement, strain, and stress fields. 


\section{CHAPTER 3}

\section{STRAIN ENERGY RELEASE RATE CALCULATION}

Once the stress, strain, and displacement fields are known in the adhesive-bonded singlelap composite joints, the VCCT is applied to estimate the SERR of the joint with a prescribed crack. According to linear elastic fracture mechanics, the energy released from the propagation of a small crack is equivalent to the work needed to close that small crack propagation. Cracks usually start at locations of high stress concentration. For the ASTM D3165 specimen configuration shown in Fig. 2.1, the critical area is located at the lower part of the junction between Adherend Portions 3 and 4. Often times, it is either the adhesive/adherend interface below the junction that starts to fail, in the case of metal adherends, or the adherend that starts to fail at the junction, in the case of composite adherends. Failure of such joints at the adherend/adhesive interface with either thin or thick bondlines has been studied by Yang et al.[38,39] Because the focus of this current study is on the first-ply failure of the adherend, the failure is assumed to initiate at the junction of Adherend Portions 3 and 4 and at the first ply from the adhesive. Thereafter, the crack propagates along the length direction of the joint until the entire joint unzip.

\subsection{Analytical Approach}

In derivation of the expression for the SERR, a joint is assumed to have an overlap length $l_{o}$, a notch size $L_{2}$, and a crack length $a$, which is located at the interface of the first ply of the upper adherend, as shown in Fig. 3.1. The displacement of the crack tip $C$, after a load is applied, can be determined using the mechanical model previously described with an overlap region length of $L_{4}=l_{o}-a$. 


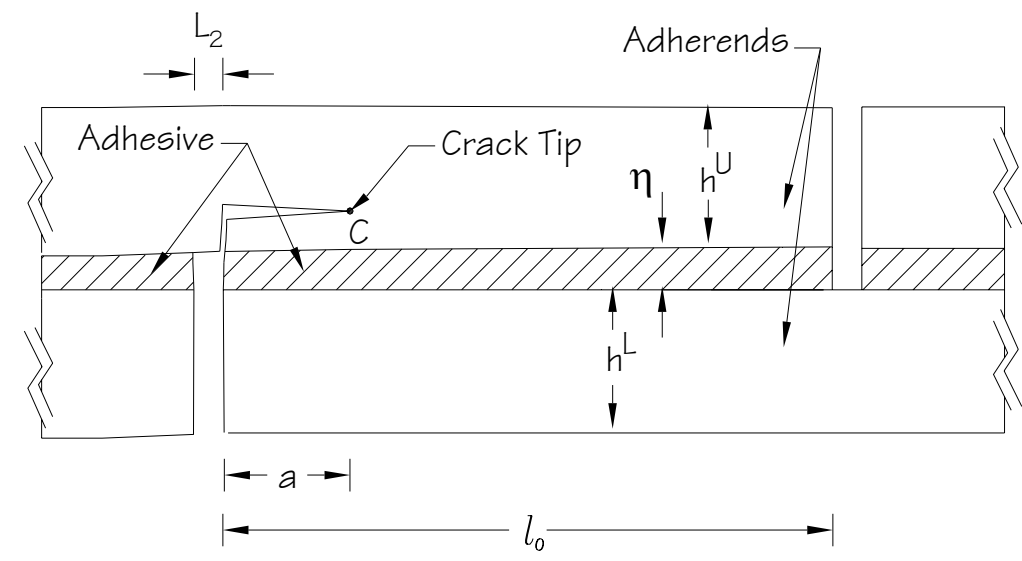

Figure 3.1 ASTM D3165 specimen with initial crack of length $a$.

Interlaminar and adhesive stress distributions can be determined using the solution from the analytical model described previously. Before the crack growth of an additional small length $b$, as shown in Fig. 8, the first ply between $C^{\prime}$ and $C$ adheres to the upper adherend where interlaminar shear and peel stresses exist at the interface, as shown on the left side of Fig. 3.2.

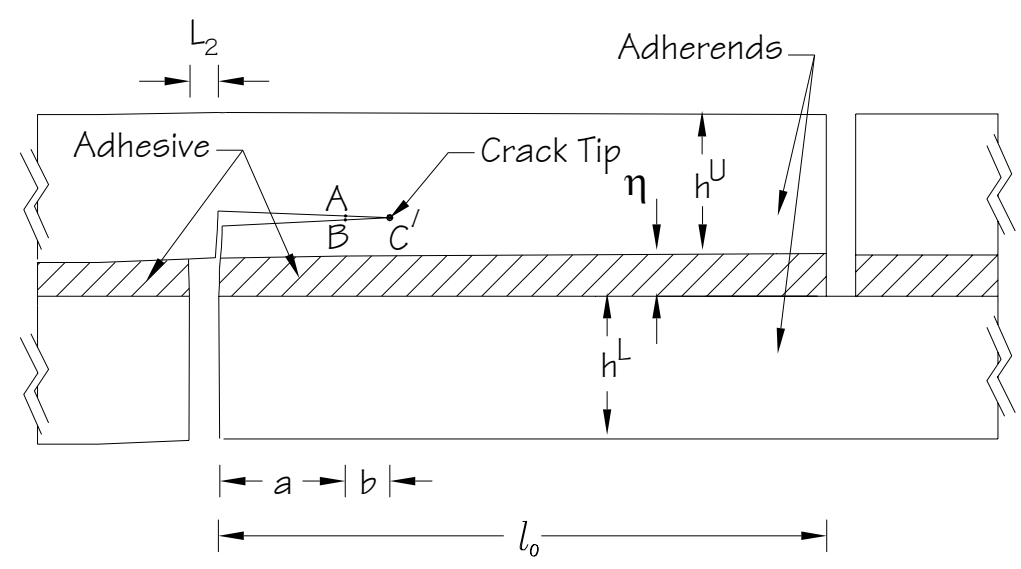

Figure 3.2 ASTM D3165 specimen with a virtual crack extension of length $b$. 


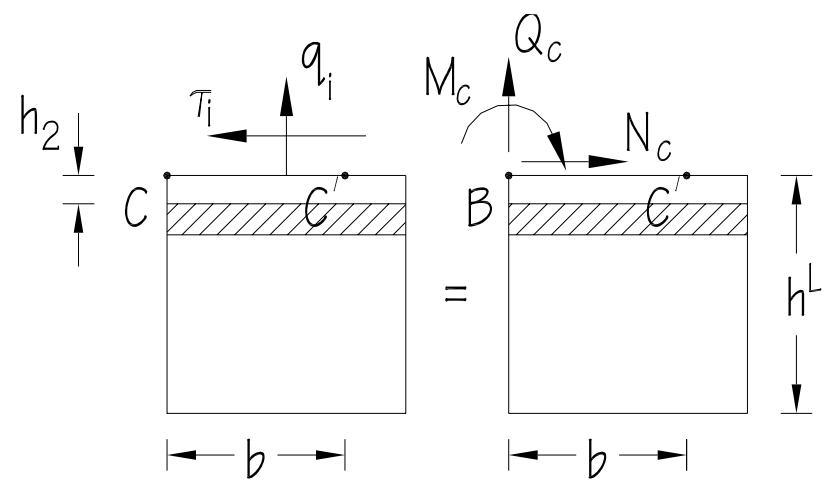

Figure 3.3 Equivalent forces at the crack tip.

The interlaminar shear and peel stresses between $C^{\prime}$ and $C$ vanish after the crack propagates a small length $b$. The equivalent crack-tip forces $N_{C}, M_{C}$, and $Q_{C}$, corresponding to a small crack propagation $b$, are related to the shear and peel stresses between $C^{\prime}$ and $C$, as shown on the right side of Fig. 3.3, and can be calculated as

$$
\begin{gathered}
N_{C}=\int_{0}^{b} \tau_{i} d x_{4} \\
M_{C}=-\int_{0}^{b} q_{i} x_{4} d x_{4} \\
Q_{C}=-\int_{0}^{b} q_{i} d x_{4}
\end{gathered}
$$

where the interlaminar shear stress $\tau_{i}$ and peel stress $q_{i}$ are obtained from the stress model with an overlap length $L_{4}=l_{o}-a$. Note that only the first ply, adhesive layer, and lower adherend are shown in Fig. 3.3 and that the positive directions of $N_{C}, M_{C}$, and $Q_{C}$ are defined to be consistent with the positive directions of displacements $u, \psi$, and $w$, respectively.

After the crack propagates, a small length $b$, the previous crack tip $C$ separates into two points $A$ and $B$, as shown in Fig. 3.2. To determine the relative displacement between points $A$ and $B$, a subsequent stress analysis is performed using a joint with a central overlap length $L_{4}=l_{o}$ $-a-b$, which simulates the overlap up to the new crack tip $C^{\prime}$. 
In order to close the virtual crack propagation (length $b$ ), crack-tip forces are applied on points $A$ and $B$ to move them back to the location of the original crack tip $C$. Therefore, the total work required to close the small crack propagation $b$ is

$$
W=\frac{1}{2}\left[N_{C}\left(u_{B}-u_{A}\right)+M_{C}\left(\psi_{B}-\psi_{A}\right)+Q_{C}\left(w_{B}-w_{A}\right)\right]
$$

For joints with a unit width, the strain energy release rate is defined as the derivative of energy released from the crack propagation with respect to the length of the crack propagation as

$$
G_{T}=\frac{d U}{d a}
$$

where $U$ is the strain energy stored in the body. Based on the VCCT, the total energy released from the crack propagation is equivalent to the work needed to close the same crack propagation. With a virtual crack propagation of length $b$, the total strain energy release rate $G_{T}$, which is a summation of the Mode I strain energy release rate $G_{I}$ and the Mode II strain energy release rate $G_{I I}$, can be calculated as

$$
G_{T}=G_{I}+G_{I I}=\frac{d U}{d a} \cong \frac{W}{b}=\frac{1}{2 b}\left[N_{C}\left(u_{B}-u_{A}\right)+M_{C}\left(\psi_{B}-\psi_{A}\right)+Q_{C}\left(w_{B}-w_{A}\right)\right]
$$

Procedure of analytical model formulation to calculate SERR has been summarized in the following flowchart 


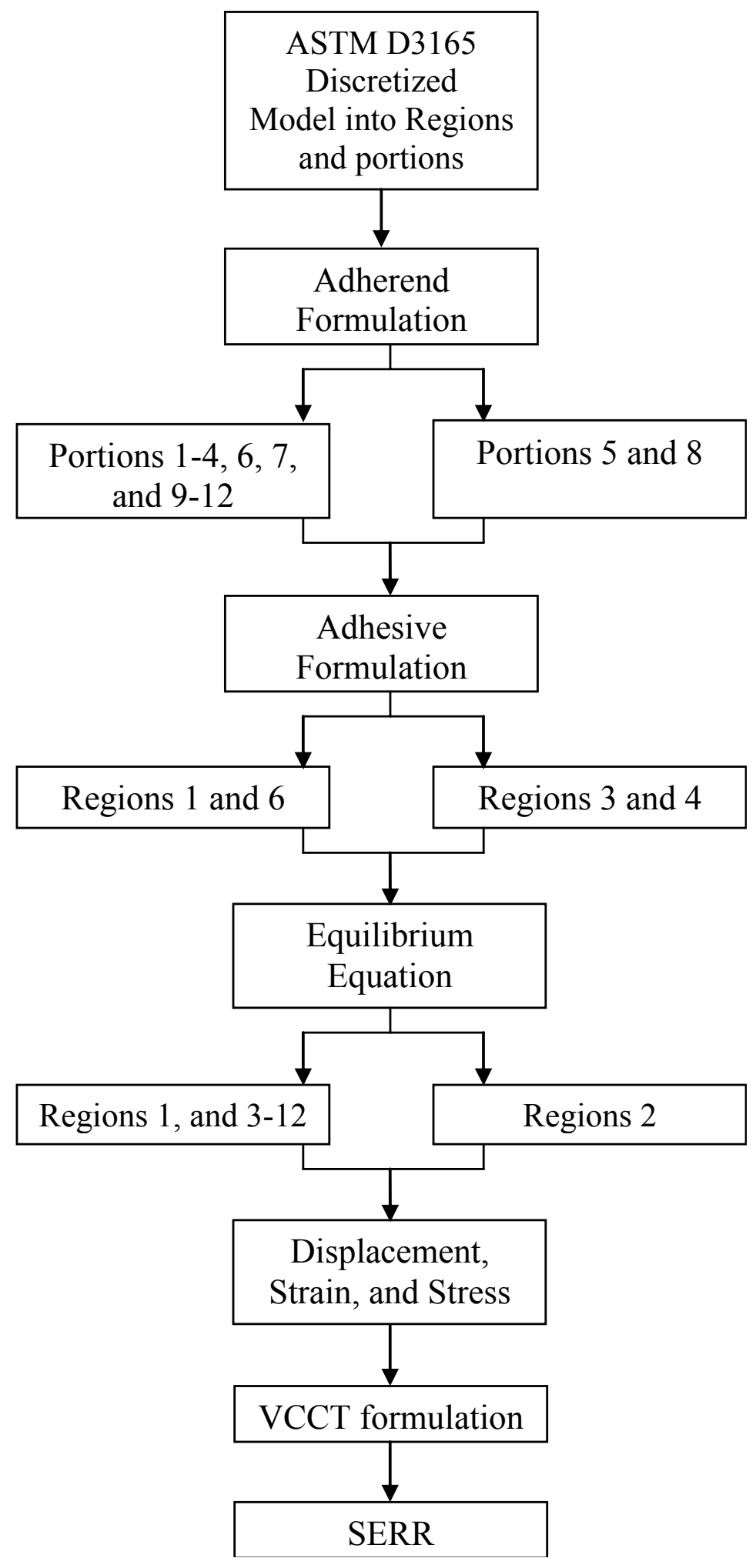

Figure 3.4 Summery of analytical approach to calculate SERR using VCCT. 


\subsection{Finite Element Approach Using VCCT}

The strain energy release rate due to the small increase in crack length is equivalent to the energy required to close that small crack increment. Therefore, the strain energy release rate can be computed by finite element models using the VCCT [58]. As shown in Fig. 3.5, the tip of a crack with an original length $a$ is located at $C$.

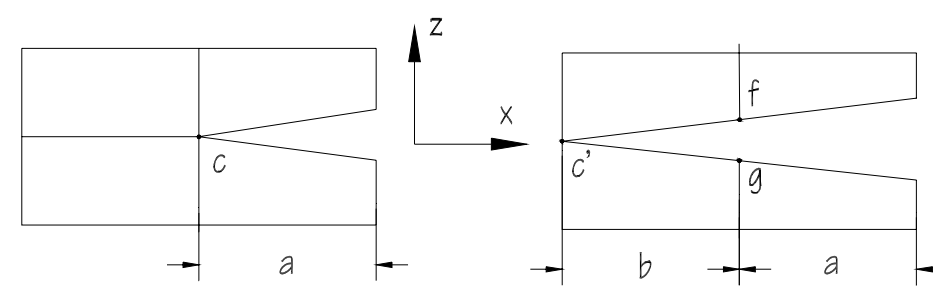

Figure 3.5 Finite element approach using VCCT.

Assuming a virtual crack propagation of length $b$, the new crack tip becomes $C^{\prime}$, and the original crack tip becomes two separate nodes $f$ and $g$. If nodes $f$ and $g$ are restrained at the original crack-tip location, this virtual crack of length $b$ is closed, and the work to close this virtual crack can be calculated by multiplying the reaction forces at nodes $f$ and $g$ by the relative displacements of these two separate nodes to the original crack tip $C$. The procedures to calculate the SERR using finite element software are described as follows:

1. Build the finite element model with an original crack of length $a$, and determine the displacements of crack tip $C, u_{c}$ and $w_{c}$ in the $x$ - and $z$-directions, respectively.

2. Propagate the crack with a small length $b$ (usually one element size); then the original crack tip $C$ becomes two separate nodes. Record the displacements of both nodes $u_{f}, w_{f}$, $u_{g}$, and $w_{g}$.

3. Constrain the two separate nodes so that they have the same displacements as the original crack tip $C$, and obtain the reaction forces $F_{x f}, F_{y f}, F_{x g}$, and $F_{y g}$.

4. The work needed to close the virtual crack is 


$$
W=\frac{1}{2}\left[F_{x f}\left(u_{c}-u_{f}\right)+F_{y f}\left(w_{c}-w_{f}\right)\right]+\frac{1}{2}\left[F_{x g}\left(u_{c}-u_{g}\right)+F_{y g}\left(w_{c}-w_{g}\right)\right]
$$

The total strain energy release rate is then obtained by

$$
G_{T}=\frac{W}{b}
$$

ABAQUS $^{\mathrm{TM}}$ has developed a VCCT subroutine called VFA [58], which calculates Modes I, II, and III strain energy release rates following a proper procedure. In the present study, twodimensional four-node linear plane-strain quadrilateral elements were utilized in the finite element model for the VCCT application. There are seven elements through the adherend thickness corresponding to seven plies of E765/T300 3KPW plane weave graphite/epoxy with orientation and sequence of $[0 / 60 /-60 / 0 /-60 / 60 / 0]$.

\subsection{Finite Element Approach Using J-Integral}

Finite element models with the $J$-integral calculation were constructed using ABAQUSTM to verify the present analytical model. The $J$-integral is usually used in quasi-static fracture analysis to characterize the energy release associated with crack propagation. It is equivalent to the strain energy release rate if the material response is linear elastic. Considering an arbitrary counter-clockwise path $(I)$ around the crack tip, as illustrated in Fig. 3.6, the $J$-integral is defined as

$$
J=\int_{\Gamma}\left(w d y-\sum_{i=1}^{3} T_{i} \frac{\partial u_{i}}{\partial x} d s\right)
$$

where $w$ is the strain energy density, $u_{1}, u_{2}$, and $u_{3}$ are the components of the displacement vector, $d s$ is the incremental length along the contour $\Gamma$, and $T_{1}, T_{2}$, and $T_{3}$ are components of the traction vector. The traction is a stress vector normal to the contour. In other words, $T_{1}, T_{2}$, and 
$T_{3}$ are the normal stresses acting at the boundary if a free-body diagram on the material inside of the contour is constructed.

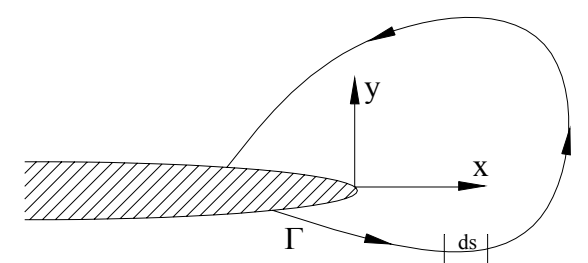

Figure 3.6 Arbitrary contour around crack tip.

Several contour integral evaluations are possible at each location along the crack front. In a finite element model, each evaluation can be thought of as the virtual motion of a block of material surrounding the crack tip. Each block is defined by contours, and each contour is a ring of elements completely surrounding the crack tip or crack front from one crack face to the opposite crack face. These rings of elements are defined recursively to surround all previous contours. ABAQUS/Standard automatically finds the elements that form each ring from the node sets given as the crack-tip or crack-front definition. Each contour provides an evaluation of the contour integral [58].

Theoretically, the $J$-integral should be independent of the domain used, but the $J$-integral estimated from different rings may vary because of the approximate nature of the finite element solution. Strong variation in these estimates, commonly called domain-dependent or contourdependent, indicates a need for mesh refinement (provided that the problem is suitable for contour integrals). Numerical tests suggest that the estimate from the first ring of elements abutting the crack front does not provide a high-accuracy result, so at least two contours are recommended. In the present study, five contours were calculated, and the average was taken as 
the final $J$-integral value. This method is quite robust in the sense that accurate contour integral estimates are usually obtained even with quite coarse meshes.

Sharp cracks, where the crack faces lie on top of one another in the unreformed configuration, are usually modeled using small-strain assumptions. Focused meshes for the $J$ integral calculation should normally be used for small-strain fracture mechanics evaluations.

For linear-elastic materials, the linear-elastic fracture mechanics (LEFM) approach predicts an $r^{-1 / 2}$ singularity near the crack tip, where $r$ is the distance from the crack tip. In finite element analyses, forcing the elements at the crack tip to exhibit an $r^{-1 / 2}$ strain singularity greatly improves accuracy and reduces the need for a high degree of mesh refinement at the crack tip [9]. This $r^{-1 / 2}$ singularity can be produced using an eight-node quadrilateral element by moving the mid-side nodes to the quarter-points, as noted by Barsoum [62] and Henshell and Shaw [63] Yang et al.[38,39] have demonstrated a complete step-by-step procedure calculating the $J$ integral using ABAQUS ${ }^{\mathrm{TM}}$. 


\section{CHAPTER 4}

\section{RESULTS AND DISCUSSION}

In the present study, ASTM D3165 was modeled analytically to determine the strain energy release rate using the methodology described previously. The symbolic solver Maple 9.52 [61] was utilized as the mathematical tool. The finite element models for the VCCT and $J$ integral were conducted using ABAQUS 6.5-1 [58] to verify the analytical results.

In order to demonstrate the application of the developed model, E765/T300 3KPW plane weave (graphite/epoxy) with a ply thickness of $0.25 \mathrm{~mm}$ and a quasi-isotropic lay-up sequence of $[60 /-60 / 0 /-60 / 60 / 0]$ was used. The engineering constants were $E_{11}=56.50 \mathrm{GPa}, E_{22}=55.20$ $\mathrm{GPa}, G_{12}=3.86 \mathrm{GPa}$, and $v_{12}=0.076$. For convenience, other mechanical properties of adherends were assumed as

$$
E_{33}=8.00 \mathrm{GPa}, G_{13}=G_{23}=3.56 \mathrm{GPa}, v_{13}=v_{23}=0.35
$$

The shear correction factor $k_{\mathrm{s}}=5 / 6$ was assumed. Two different paste adhesives with distinct moduli, Hysol EA9394 and PTM\&W ES6292, were used to fabricate the joint specimens and demonstrate the capabilities of the analytical model. Adhesives have the following material properties:

Hysol EA 9394

PTM\&W ES 6292

$$
E_{\mathrm{a}}=4.24 \mathrm{GPa}
$$

$$
E_{\mathrm{a}}=1.58 \mathrm{GPa}
$$

$$
v_{\mathrm{a}}=0.45
$$$$
v_{\mathrm{a}}=0.31
$$

The joint dimensions of the ASTM D3165 specimen includes the central overlap length $l_{o}$ $=30 \mathrm{~mm}$, notch size $L_{2}=1.6 \mathrm{~mm}$, and adherend lengths outside the central overlap $L_{1}=L_{6}=$ $78.4 \mathrm{~mm}$. Based on the thin-adhesive assumption, three different thicknesses $(\eta=0.051 \mathrm{~mm}$, $0.127 \mathrm{~mm}$, and $0.203 \mathrm{~mm}$ ) were considered in the investigation of the application of the analytical model. 
Once the stress, strain, and displacement fields were obtained, the strain energy release rates of the joints were estimated, and the solutions from the analytical models using the VCCT were compared with finite element models using the VCCT and finite element models using the $J$-integral. Tensile load $P=1.78 \mathrm{kN}$ was considered the minimum required failure load in the joint.

\subsection{Investigation of Mesh Sensitivity in Finite Element Model}

Numerical methods, such as finite element analysis, are usually mesh-sensitive. A convergence test of finite element mesh size was conducted, and the results are shown in Fig.

4.1. The converged results were used to compare with the developed analytical model.

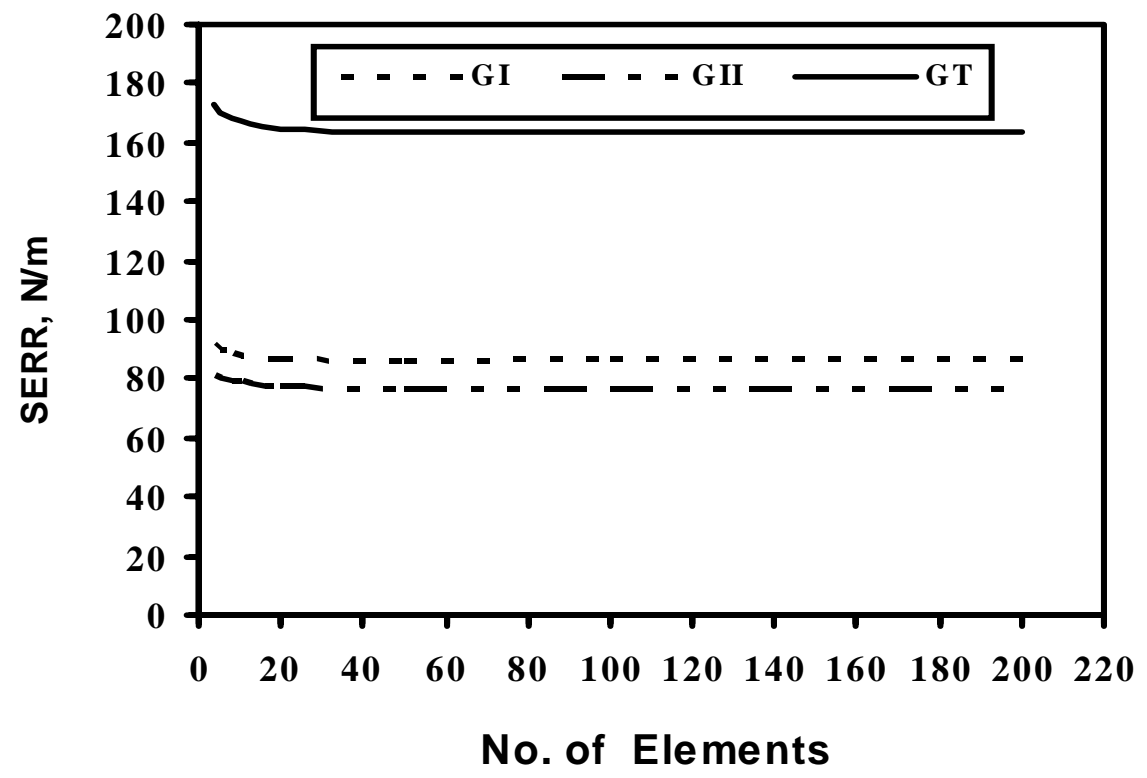

Figure 4.1 Strain energy release rate convergence of ASTM D3165 specimen versus number of elements for $\eta=0.127 \mathrm{~mm}, a=1.27 \mathrm{~mm}$, with Hysol EA 9394.

\subsection{Comparison of Mode I, Mode II and Total Strain Energy Release Rate as a function of Bondline Thickness}

Figures 4.2 and 4.3 show the SERR comparison using the VCCT, the analytical model, and the $J$-integral for different adhesive films. From these figures, it can be seen that $G_{T}$ increases with increased bondline thickness; that is, the load carrying capacity of the joint is 
lower for thicker adhesive if $G_{T}$ is critical for joint failure. Discrepancy between the analytical model and the FE models occurs for thicker bondlines. This is because the current model assumes a thin bondline and the adhesive stresses are assumed uniform through the bondline thickness. As shown in Figs. 4.4 and $4.5, G_{I}$ increases with adhesive thickness, whereas $G_{I I}$ decreases; in fact, both values compensate each other for higher values of $G_{T}$, as shown Fig. 4.2. The same trend can be observed in Figs. 4.6 and 4.7 for PTM\&W ES 6292.

\subsection{Comparison of Mode I, Mode II and Total Strain Energy Release Rate as a function of Initial Crack Length}

The strain energy release rates for three different crack lengths $(a=1.27 \mathrm{~mm}, 1.91 \mathrm{~mm}$, and $2.54 \mathrm{~mm}$ ) are shown in Figs. 4.8 and 4.9. It can be seen that $G_{T}$ decreases with increased crack length which shows the effect of crack arrest; that is, the crack would not propagate unless the load increases. If the failure criterion is set to be $G_{T}$ and because $G_{T}$ decreases with longer crack length, a stable crack growth can be expected. Figures 21 and 22 show variations of Mode I and Mode II for Hysol EA 9394. It can be concluded that either using Mode I or Mode II as the failure criterion, a stable crack growth is expected.

It can be seen that results from the finite element models with the VCCT and $J$-integral are identical and show the same trend for thin adhesives, while the developed analytical model deviates about 10 percent from the finite element models. The deviation between finite element analysis and the analytical model comes from the assumption of the constant stresses through the thickness of the adhesive. 


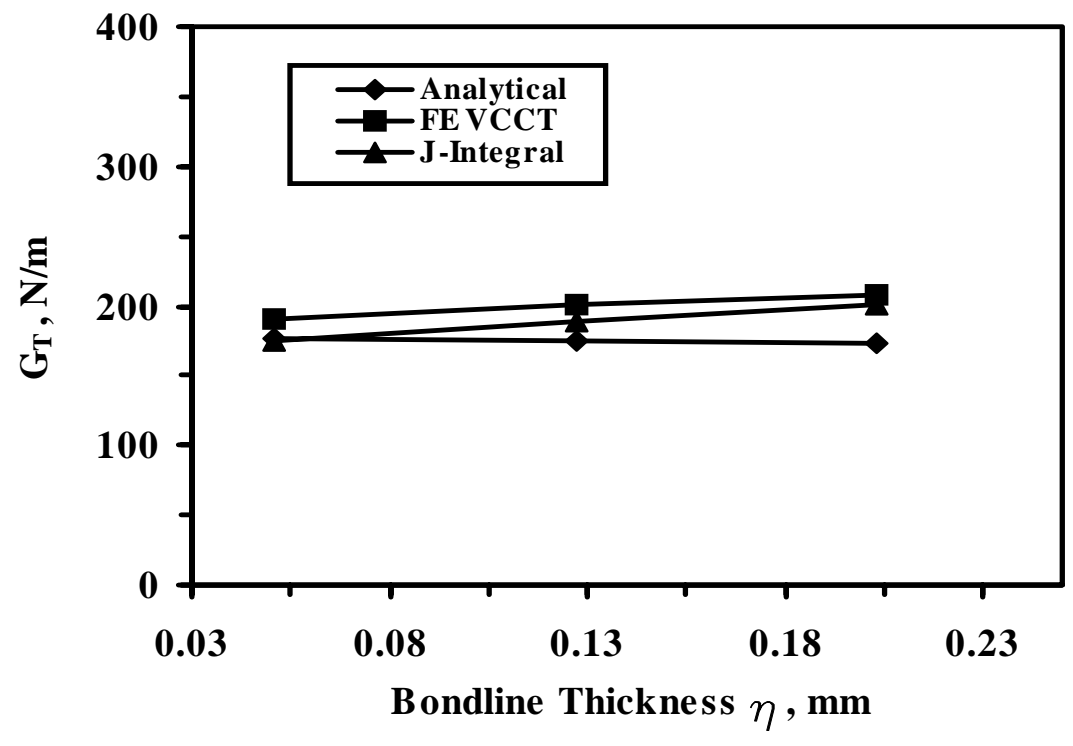

Figure 4.2 Strain energy release rate of ASTM D3165 specimen as a function of bondline thickness for $a=1.27 \mathrm{~mm}$ with Hysol EA 9394 adhesive.

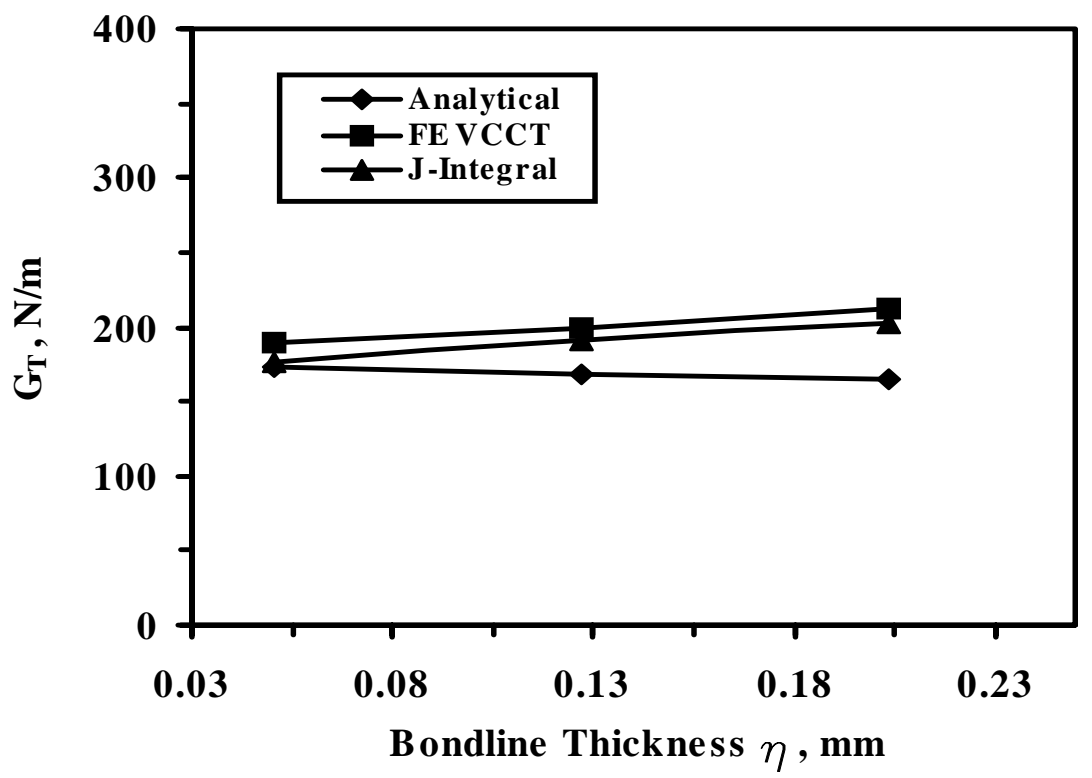

Figure 4.3 Strain energy release rate of ASTM D3165 specimen as a function of bondline thickness for $a=1.27 \mathrm{~mm}$ with PTM\&W ES 6292 adhesive. 


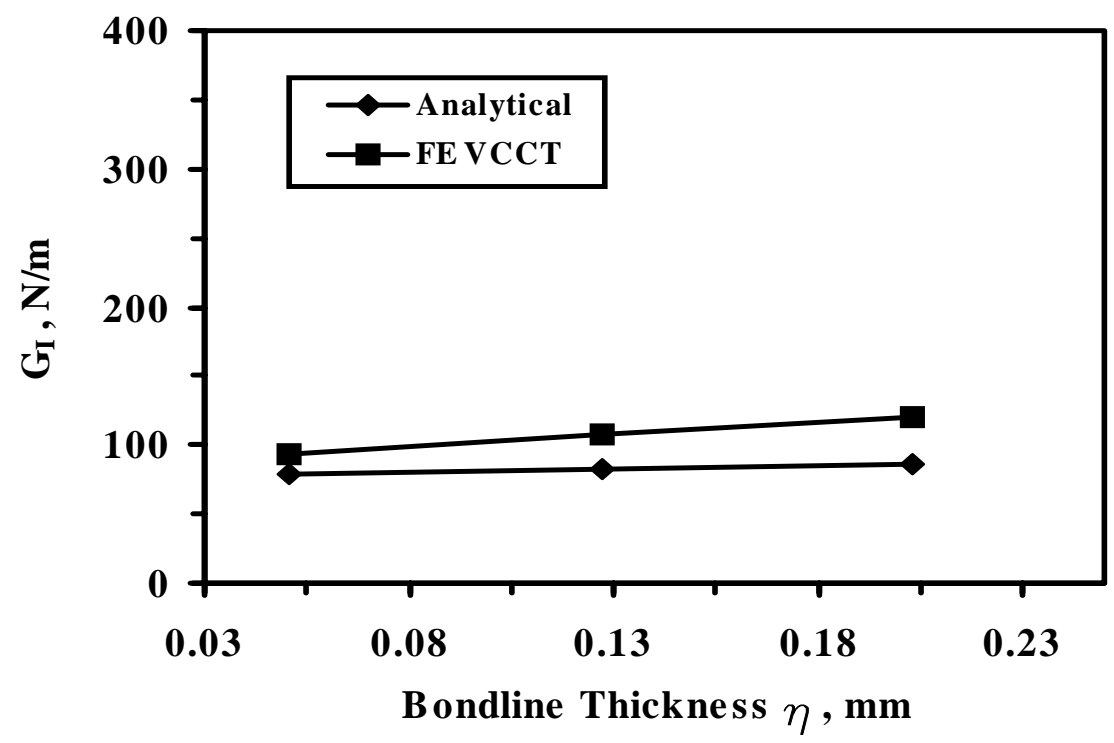

Figure 4.4 Mode I strain energy release rate of ASTM D3165 specimen as a function of bondline thickness for $a=1.27 \mathrm{~mm}$ with Hysol EA 9394.

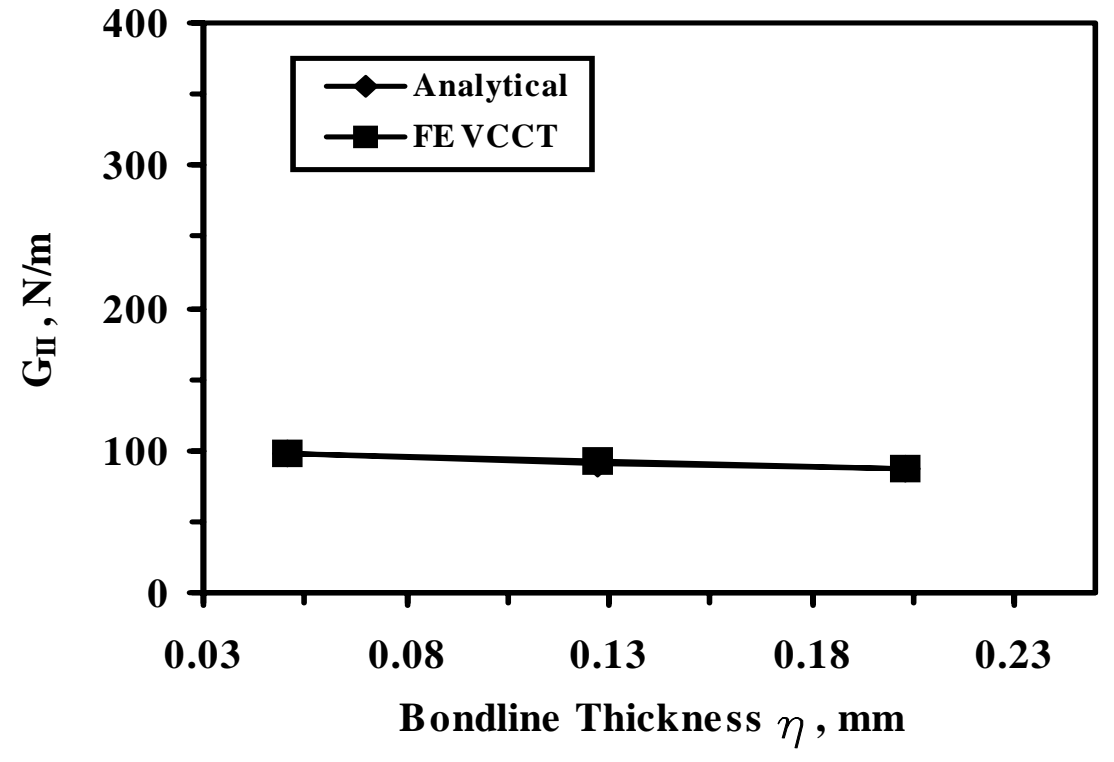

Figure 4.5 Mode II strain energy release rate of ASTM D3165 specimen as a function of bondline thickness for $a=1.27 \mathrm{~mm}$ with Hysol EA 9394. 


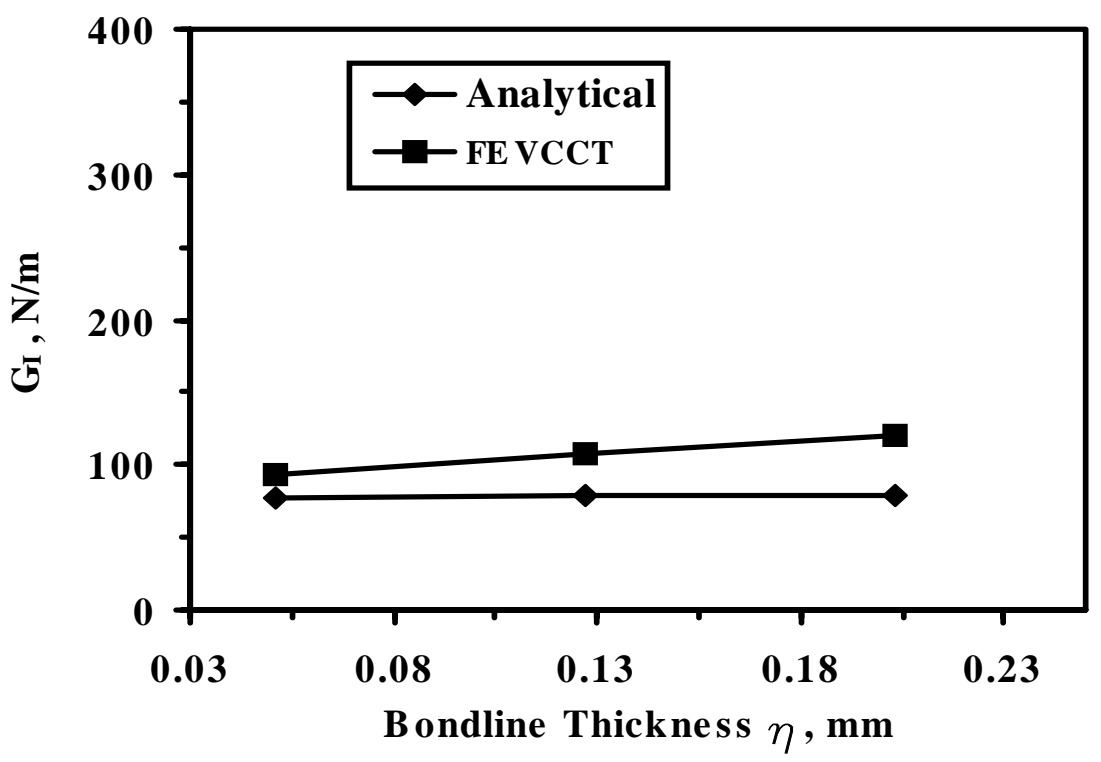

Figure 4.6 Mode I strain energy release rate of ASTM D3165 specimen as a function of bondline thickness for $a=1.27 \mathrm{~mm}$ with PTM\&W ES 6292.

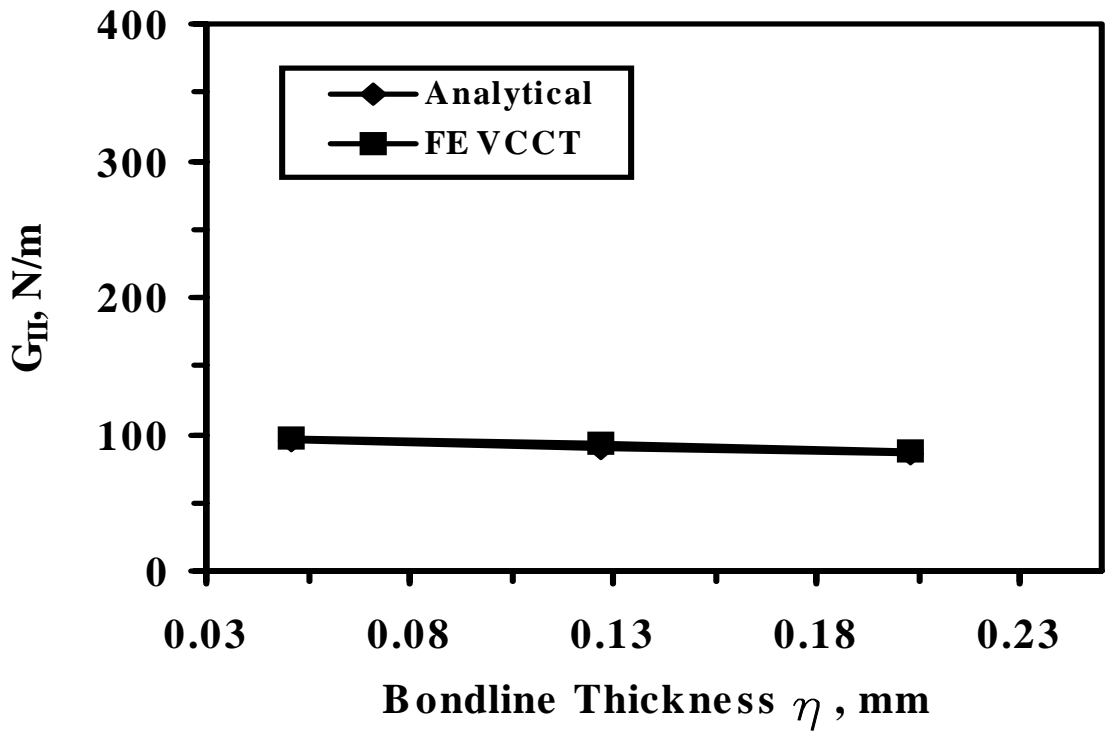

Figure 4.7 Mode II strain energy release rate of ASTM D3165 specimen as a function of bondline thickness for $a=1.27 \mathrm{~mm}$ with PTM\&W ES 6292 . 


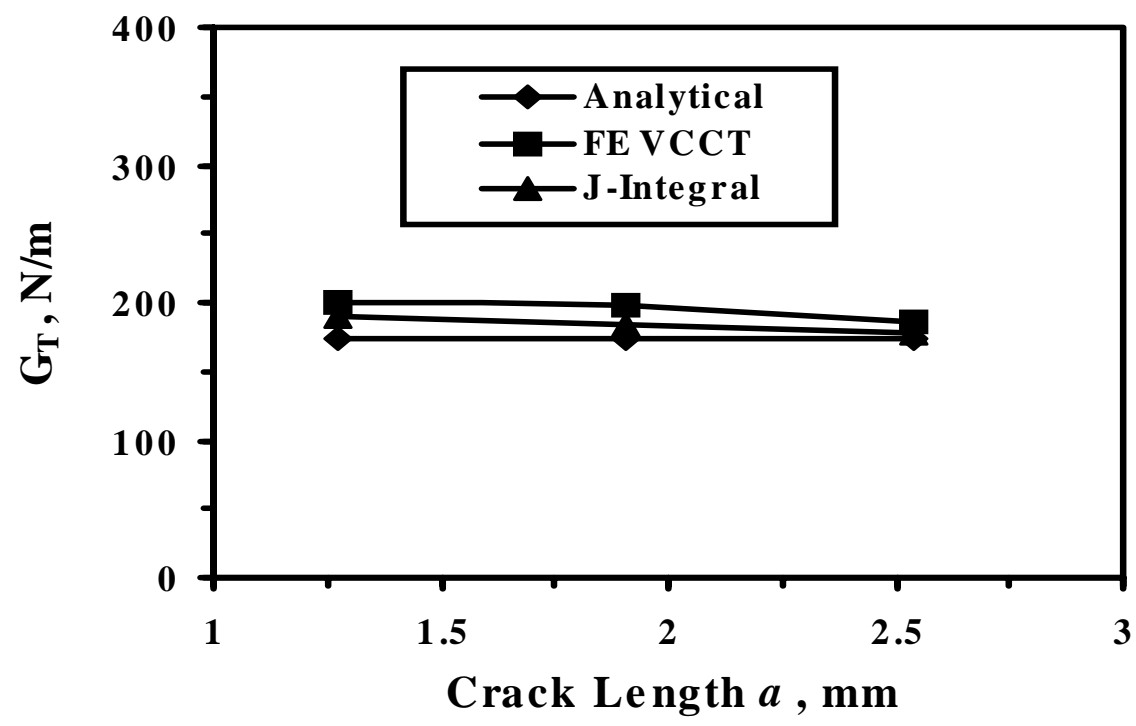

Figure 4.8 Strain energy release rate of ASTM D3165 specimen as a function of initial crack length for $\eta=0.127 \mathrm{~mm}$ with Hysol EA 9394 .

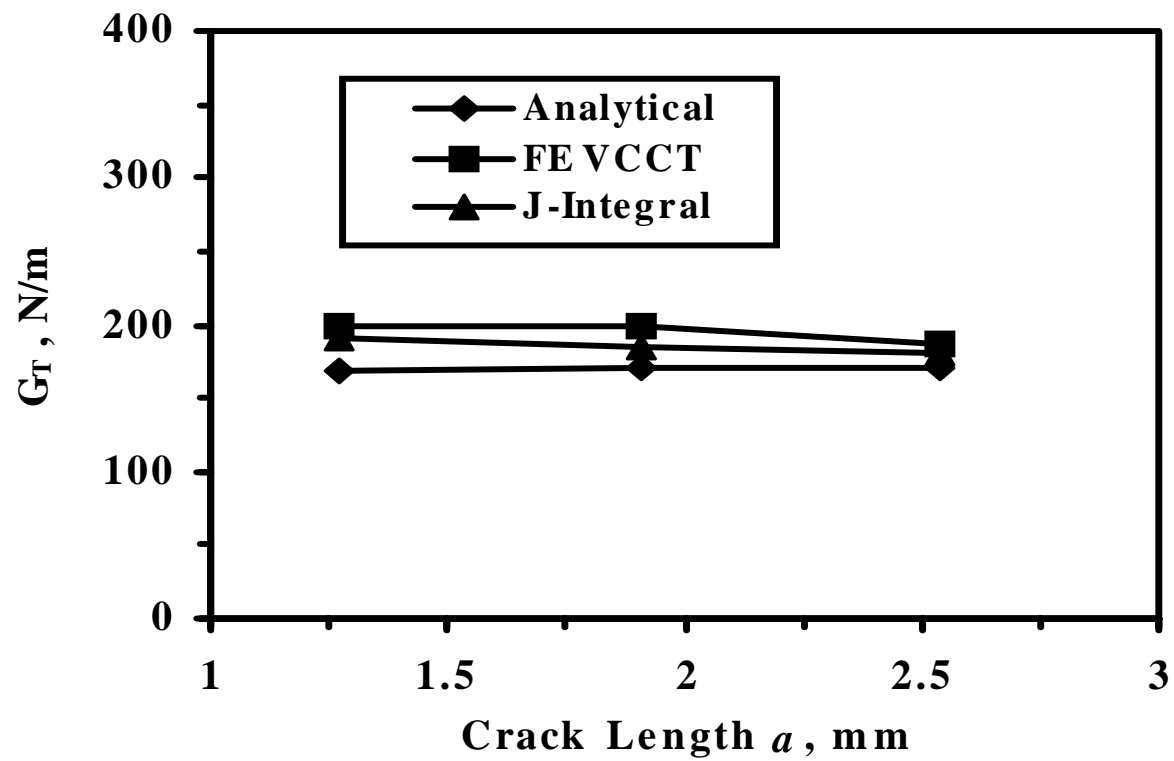

Figure 4.9 Strain energy release rate of ASTM D3165 specimen as a function of initial crack length for $\eta=0.127 \mathrm{~mm}$ with PTM\&W ES 6292. 


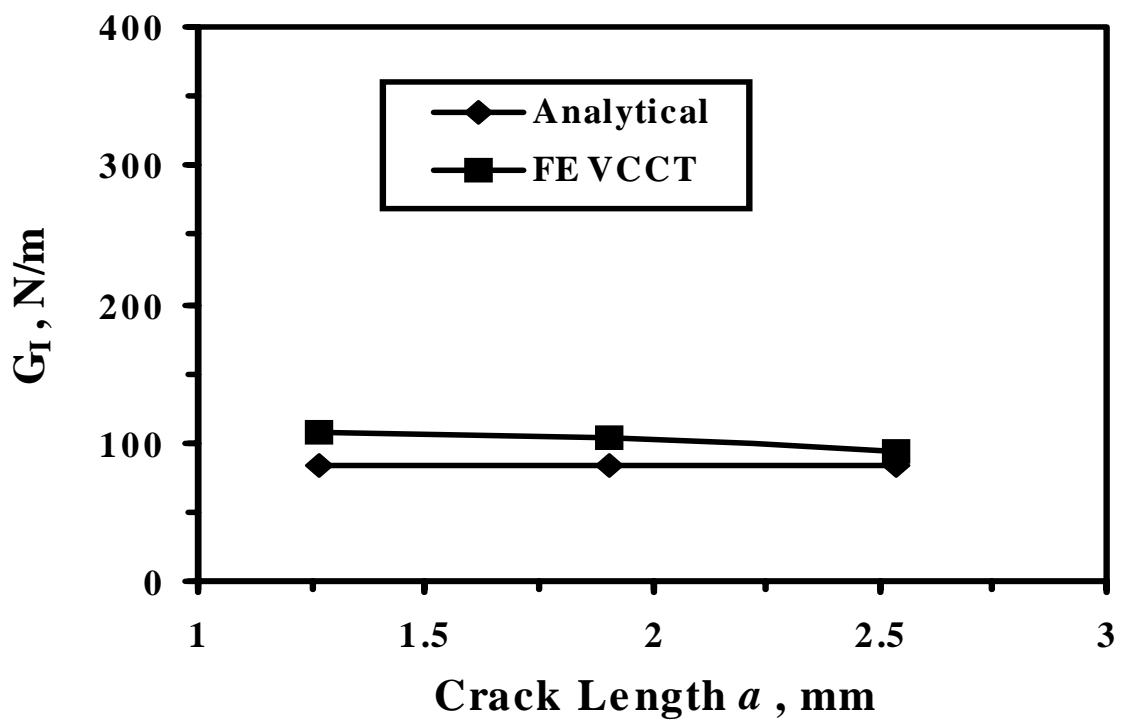

Figure 4.10 Mode I Strain energy release rate of ASTM D3165 specimen as a function of initial crack length for $\eta=0.127 \mathrm{~mm}$ with Hysol EA 9394.

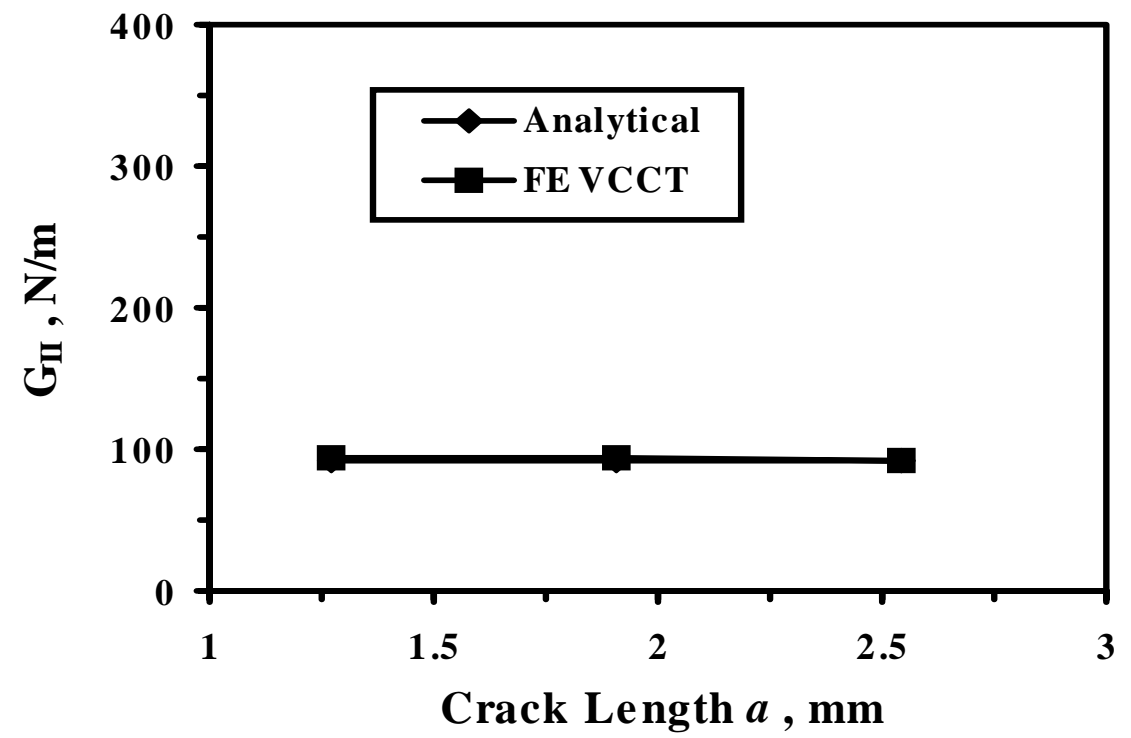

Figure 4.11 Mode II Strain energy release rate of ASTM D3165 specimen as a function of initial crack length for $\eta=0.127 \mathrm{~mm}$ with Hysol EA 9394 . 


\section{CHAPTER 5}

\section{CONCLUSION AND RECOMMENDATIONS}

\subsection{Conclusion}

An analytical method was developed to calculate the strain energy release rate based on ASTM D3165 specimen geometry with a prescribed interlaminar crack. The stress and displacement fields for the adhesive-bonded single-lap composite joint were determined based on the laminated anisotropic plate theory. The virtual crack closure technique (VCCT) was applied effectively in conjunction with the analytical stress and displacement models in determining the strain energy release rate (SERR). Results obtained from the developed analytical method correlated properly with results from the finite element models using both the VCCT and $J$-integral. Therefore, the present study has given a description of a reasonably accurate, rapid-solution method for calculating the SERR of an adhesive-bonded single-lap composite joint.

\subsection{Recommendations}

- The analytical model can be further enhanced to consider the thick-bondline formulations.

- The analytical model developed can be verified as a failure criterion for failure analysis of adhesive-bonded composite joints due to delamination. 
REFERENCES 


\section{LIST OF REFERENCES}

[1] Irwin, G. R., "Plastic Zone Near a Crack and Fracture Toughness," Sagamore Research Conference Proceedings, Vol.4, Syracuse University Institute, Syracuse, NY, 1961, pp.6378.

[2] Dugdale, D. S., "Yielding in Steel Sheets Containing Slits," Journal of the Mechanics and Physics of Solids, Vol.8, 1960, pp.100-104.

[3] Barenblatt, G. I, "The Mechanical Theory of Equlibrium Cracks in Brittle Fracture," Advances in Applied Mechanics, Vol. VII, Academic Press, 1962, pp.55-129.

[4] Wells, A. A., "Unstable Crack Propagation in Metals: Cleavage and Fast Fracture," Proceedings of the Crack Propagation Symposium, Vol. 1, paper 84, Cranfield, UK,1961.

[5] Rice, J. R., "A path Independent Integral and the Approximate Analysis of Strain Concentration by Notches and Cracks," Journal of Applied Mechanics, Vol. 35, 1968, pp. 379-386.

[6] Huchinson, J. W., "Singular Behavior at the End of a Tensile Crack Tip in a Hardening Material," Journal of the Mechanics and Physics of Solids, Vol. 16, 1968, pp. 13-31.

[7] Rice, J. R. and Rosengren, G. F., "Plane Strain Deformation near a Crack Tip in a PowerLaw Hardening Material," Journal of the Mechanics and Physics of Solids, Vol. 16, 1968, pp. 1-12.

[8] Shih, C. F. and Huchinson, J. W., "Fully Plastic Solutions and Large-Scale Yielding Estimates for Plane Stress Crack Problems," Journal of Engineering Materials and Technology, Vol. 98, 1976, pp. 289-295.

[9] Anderson, T. L., Fracture Mechanics: Fundamentals and Applications, $3^{\text {rd }}$ ed., CRC Press LLC, Boca Raton, FL, 2005.

[10] Griffith, A. A., "The Phenomena of Rupture and Flow in Solids," Philosophical Transactions, Series A, Vol.221, 1920, pp. 498-528.

[11] Irwin, G. R., "Onset of Fast Crack Propagation in High Strength Steel and Aluminum Alloys," Sagamore Research Conference Proceedings,Vol.2, 1956, pp.289-305.

[12] Parton, V. Z., Man L., Fracture Mechanics: From Theory to Practice, Gordon and Breach Science Publishers, 1992.

[13] Bradley, W. L., "Understanding the Translation of Near Resin Toughness into Delamination Toughness in Composites," Key Engineering Materials, Vol. 37, 1989, pp. 161-198. 
[14] Rosen, B. W., "Mechanics of Composite Strengthening ," Fiber Composite Materials, American Society for Metals, Metals Park, OH, 1965, pp. 37-75.

[15] Highsmith, A. L. and Davis, J., "The Effects of Fiber Waviness on the Compressive Response of Fiber-Reinforced Composite Materials," Progress Report for NASA Research Grant NAG-1-659, NASA Langley Research Center, Hampton, VA, 1990.

[16] Wang, A. S. D., “A Non-Linear Microbuckling Model Predicting the Compressive Strength of Unidirectional Composites," ASME Paper 78-WA/Aero-1, American Society for Mechanical Engineers, New York, 1978.

[17] Guynn, E. G., "Experimental Observations and Finite Element Analysis of the Initiation of Fiber Microbuckling in Notched Composite Laminates," Ph.D. Dissertation, Texas A\&M University, College Station, TX, 1990.

[18] Whitney, J. M., Browning, C. E., and Hoogsteden, W., “ A Double Cantilever Beam Test for Characterizing Mode I Delamination of Composite Materials," Journal of Reinforced Plastics and Composites, Vol. 1, 1982, pp. 297-313.

[19] Prel, Y. J., Davies, P., Benzeggah, M. L., and de Charentenay, F.-X., "Mode I and Mode II Delamination of Thermosetting and Thermoplastic Composites," ASTM STP 1012, American Society for Testing and Materials, Philadelphia, PA, 1989, pp. 251-269.

[20] Corleto, C. R. and Bradley, W. L. ,'Mode II Delamination Fracture Toughness of Unidirectional Graphite/Epoxy Composites," ASTM STP 1012, American Society for Testing and Materials, Philadelphia, PA, 1989, pp. 201-221.

[21] D5528-01, "Standard Test Method for Mode I Interlaminar Fracture Toughness of Unidirectional Fiber-Reinforced Polymer Matrix Composites," American Society for Testing and Materials, Philadelphia, PA, 2001.

[22] Westergaard, H. M., "Bearing Pressures and Cracks," Journal of Applied Mechanics, Vol. 6, 1939, pp. 49-53.

[23] Williams, M. L., "On the Stress Distribution at the Base of a Stationary Crack," Journal of Applied Mechanics, Vol. 24,1957, pp. 109-114.

[24] Kobayashi, A. S., Cherepy, R. B., and Kinsel, W. C.,"A Numerical Procedure for Estimating the Stress Intensity Factor of a Crack in a Finite Plate," Journal of Basic Engineering, Vol. 86, 1964, pp. 681-684.

[25] Parks, D. M., “A Stiffness Derivative Finite Element Technique for Determination of Crack Tip Stress Intensity Factors," International Journal of Fracture, Vol. 10, 1974, pp. 487-502. 
[26] deLorenzi, H. G., "On the Energy Release Rate and the J-Integral of 3-D Crack Configuration,” International Journal of Fracture, Vol. 19, 1982, pp. 183-193.

[27] deLorenzi, H. G., "Energy Release Rate Calculations by the Finite Element Method," Engineering Fracture Mechanics, Vol. 21, 1985, pp. 129-143.

[28] Luo, Q. and Tong, L., "Fully-coupled nonlinear analysis of single lap adhesive joints," International Journal of Solids and Structures, Vol. 44, No.7-8, 2007, pp. 2349-2370.

[29] Palazotto, A. and Birman, V. "Review of Fracture in Adhesive Joints Considering Rocket Motor Application," Journal of Spacecraft and Rockets, Vol. 32, No. 3, May-June 1995, pp. 538-544.

[30] De Goejj, W. C., Van Tooren, M. J. L., and Beukers, A. "Composite Adhesive Joints Under Cyclic Loading,” Material and Design, Vol. 20, 1999, pp. 213-221.

[31] Sheppard, A., Kelly, D. and Tong, L., "A Damage Zone Model for the Failure Analysis of Adhesively Bonded Joints," International Journal of Adhesion and Adhesives, Vol. 18, 1998, pp. 385-400.

[32] Sun, W., "Analysis of Energy Release Rate for Adhesive-Bonded Single-Lap Composite Joints," Master Thesis, Wichita State University, Wichita, KS, August 2004.

[33] Adams, R. D. and Davies, R., "Strength of Joint involving Composites," Journal of Adhesion, Vol. 59, 1996, pp. 171-182.

[34] Armanios, E. A., "Analysis of Delamination Related Fracture Processes in Composites," Preliminary Final Report, NAS 1.26184603, NASA-CR-184603, 2005.

[35] Armanios, E. A., and Rehfield, L. W., "Interlaminar Analysis of Laminated Composites Using a Sublaminate Approach," Proceedings of the AIAA/ASME/ASCE/AHS 27th Structures, Structural Dynamics, and Materials (SDM) Conference, San Antonio, Texas, May 1986, AIAA Paper No. 86-0969CP, Part 1, pp. 442-452.

[36] Wikimedia, Website: http://upload.wikimedia.org/wikipedia/en/9/9e/Adhesive2.jpg.

[37] Armanios, E. A., and Rehfield, L. W., "A Simplified Approach to Strain Energy Release Computations for Interlaminar Fracture of Composites," Proceedings of the Fourth JapanU.S. Conference on Composite Materials, Washington, D. C., 1988, pp. 285-296.

[38] Yang, C., Sun, W., Tomblin, J. S., and Smeltzer, S. S. II, "A Semi-analytical Method for Determining the Strain Energy Release Rate of Cracks in Adhesively Bonded Single-Lap Composite Joints," Journal of Composite Materials, Vol. 41, No. 13, pp. 1579-1602, 2007. 
[39] Yang, C., Chadegani, A., Tomblin, J. S., "Strain Energy Release Rate Determination of Prescribed Cracks in Adhesively Bonded Single-Lap Composite Joints with Thick Bondlines," In Press, Composites Part B: Engineering, 2008.

[40] Kutscha, D., "Mechanics of Adhesive-Bonded Lap-Type Joints: Survey and Review," Technical Report AFML-TDR-64-298, 1964.

[41] Kutscha, D., and Hofer, K. E., Jr., "Feasibility of Joining Advanced Composite Flight Vehicles," Technical Report AFML-TR-68-391, 1969.

[42] Matthews, F. L., Kilty, P. F., and Goodwin, E. W., "A Review of the Strength of Joints in Fiber-Reinforced Plastics: Part 2 Adhesively Bonded Joints," Composites, Vol. 29, 1982.

[43] Vinson, J. R., "Adhesive Bonding of Polymer Composites," Polymer Engineering and Science, Vol. 29, pp. 1325, 1989.

[44] Yang, C., and Pang, S. S., "Stress-Strain Analysis of Single-Lap Composite Joints under Tension," ASME Transaction, Journal of Engineering Materials and Technology, Vol. 118, 1996, pp. 247-255.

[45] Huang, H., Yang, C., Tomblin, J. S., and Harter, P., "Stress and Failure Analyses of Adhesive-Bonded Composite Joints using ASTM D3165 Specimens," ASTM Journal of Composites Technology \& Research, Vol. 24, No. 2, 2002, pp. 345-356.

[46] Yang, C., Huang, H., Tomblin, J. S., and Sun, W., "Elastic-Plastic Model of AdhesiveBonded Single-Lap Composite Joints," Journal of Composite Materials, Vol. 38, No. 4 2004, pp. 293-309.

[47] Yang, C., Tomblin, J. S., and Guan, Z., "Analytical Modeling of ASTM Lap Shear Adhesive Specimens," Technical Report, DOT/FAA/AR-02/130, 2003.

[48] Harter, P., "Investigation of Adhesive Test Methods for Thick Bondline Joints," Master Thesis, Wichita State University, Wichita, KS, May 2000.

[49] Yang, C. Tomblin, J. S., "Investigation of Adhesive Behavior in Aircraft Application," Technical Report, DOT/FAA/AR-01/57, 2001.

[50] O' Brien, T. K., "Characterization of Delamination Onset and Growth in a Composite Laminate," International Journal of Mechanical Sciences, Vol.15, 1973, pp-679-688.

[51] Wilkins, D. J., Eisemann, J. R., Camin, R. A., Margolis, W. S. and Benson, R. A., "Characterizing Delamination Growth in Graphite-Epoxy ," Damage in Composite Materials, ASTM STP 775, K. L. Reifsnider, Ed., American Society for Testing and Materials,1984, pp. 125-142. 
[52] Wang, S. S. and Choi, I., "The Mechanics of Delamination in Fiber-Reinforced Composite Materials, Part II- Delamination Behavior and Fracture Mechanics Parameters," NASA CR-172270, Nov. 1983.

[53] Wang, S. S. and Choi, I., "Edge Delamination in Angle-Ply Composite Laminates," Proceedings of the AIAA/ASME/ASCE/AHS $22^{\text {nd }}$ Structure, Structural Dynamics, and Material Conference, April 6-8, 1981, Atlanta, Georgia, pp-473-484.

[54] Valisetty, R. R. and Rehfield L. W., "A New Approach to Interlaminar Stress Analysis," Delamination and Debonding of Materials, ASTM STP 876, W. S. Johnson, Ed., American Society for Testing and Materials, 1985.

[55] Rehfield, L. W., Armanios, E. A., and Weinstein, F., "Analytical Modeling of Interlaminar Fracture in Laminated Composites," Composites '86: Recent Advances in Japan and the United States, Proceedings of the Third Japan-U.S. Conference on Composite Materials, K. Kawata, S. Umekawa, and A. Kobayashi, eds., 1986 , pp. 331-340.

[56] Wang, J. T., Xue, D. Y., Sleight, D. W., and Housner, J. M., "Computation of Energy Release Rate for Cracked Composite Panels with Nonlinear Deformation," Proceedings of AIAA/ASME/ASCE/AHS/ASC Structures, Structural Dynamics \& Materials Conference, No. 4, pp. 2713-2727, 1995.

[57] Wei, Y., Yang, T., Wan, Z., and Du, X., "New VCCT and Its Application in Composite Delamination Analysis," Chinese Journal of Computational Mechanics, Vol. 17, No. 3, 2000, pp. 308-312.

[58] ABAQUS/CAE User Manual and VFA Package, Version 6.5-1, Hibbit, Karlsson \& Sorensen Inc., Providence, R.I, 2004-2005.

[59] "Strength Properties of Adhesives in Shear by Tension Loading of Single-Lap-Joint Laminated Assemblies," ASTM D3165-95.

[60] Krueger, D., "The Virtual Crack Closure Technique: History, Approach and Applications," Technical Report NASA/CR-2002-211628, ICASE Report No.2002-10, 2002.

[61] Maple 9.52, Waterloo Maple Inc., Ontario, Canada, 2005.

[62] Barsoum, R. S., "On the Use of Iso-parametric Finite Elements in Linear Fracture Mechanics," International Journal for Numerical Methods in Engineering, Vol. 10, 1976, pp. 25-37.

[63] Henshell, R. D., and Shaw, K. G., "Crack Tip Finite Elements are Unnecessary," International Journal for Numerical Methods in Engineering, Vol. 9, 1975, pp. 495-507. 
[64] Kim, I.-G., and Kong, C.-D., "Generalized Theoretical Analysis Method for Free-Edge Delaminations in Composite Laminates," Journal of Materials Science, Vol. 37, 2002 pp. $1875-1880$.

[65] Rybicki, E. F., and Kanninen, M.F., "A Finite Element Calculation of Stress Intensity Factors by a Modified Crack Closure Integral," Engineering Fracture Mechanics, Vol. 9, 1977, pp. 931-938.

[66] Raju, I. S., "Calculation of Strain-Energy Release Rates With Higher Order and Singular Finite Elements," Engineering Fracture Mechanics, Vol. 28, 1987, pp. 251-274.

[67] Avalia A. F. and Bueno P. de O. "An experimental and numerical study on adhesive joints for composites," Composite Structures, Vol. 64, 2004, pp. 531-537.

[68] Park, O., and Sankar, B. V., "Crack-Tip Force Method for Computing Energy Release Rate in Delaminated Plates," Composite Structures, Vol. 55, 2002, pp. 429-434.

[69] Chadegani, A., Yang, C., Dan-Jumbo, E.," Strain Energy Release Rate Analysis Of Adhesive-Bonded Composite Joints with a Prescribed Interlaminar Crack," Proceedings of the AIAA/ASME/ASCE/AHS $49^{\text {th }}$ Structures, Structural Dynamics, and Materials (SDM) Conference, Schaumburg, Illinois, April 7-10 2008, AIAA Paper No. 2008-1846.

[70] Hart-Smith, L. J., "Adhesive-Bonded Single-Lap Joints," Douglas Aircraft Company, NASA Langley Report CR 112236, 1973. 
APPENDIX 


\section{Boundary Conditions}

\section{Region 1}

$$
\begin{gathered}
\left.u_{1}^{o}\right|_{x_{1}=0}=0 \\
\left.w_{1}\right|_{x_{1}=0}=0 \\
\left.M_{1 y}\right|_{x_{1}=0}=0 \\
=\frac{A_{11}^{U}}{A_{11}^{U}+A_{11}^{L}+E_{a} \eta} P \\
\left.M_{2 y}\right|_{x_{1}=0}=0 \\
\left.Q_{2 z}\right|_{x_{1}=L_{1}}=0 \\
\left.M_{2 y}\right|_{x_{1}=L_{1}}=0 \\
\left.N_{2 x}\right|_{x_{1}=L_{1}}=0
\end{gathered}
$$

\section{Region 3}

$$
\begin{aligned}
& \left.u_{3}^{o}\right|_{x_{2}=L_{2}}=\left.u_{4}^{o}\right|_{x_{3}=0} \\
& \left.w_{3}\right|_{x_{2}=L_{2}}=\left.w_{4}\right|_{x_{3}=0}
\end{aligned}
$$




$$
\begin{aligned}
& \left.\psi_{3}\right|_{x_{2}=L_{2}}=\left.\psi_{4}\right|_{x_{3}=0} \\
& \left.N_{3 x}\right|_{x_{2}=L_{2}}=\left.N_{4 x}\right|_{x_{3}=0} \\
& \left.M_{3 y}\right|_{x_{2}=L_{2}}=\left.M_{4 y}\right|_{x_{3}=0} \\
& \left.Q_{3 z}\right|_{x_{2}=L_{2}}=\left.Q_{4 z}\right|_{x_{3}=0} \\
& \left.N_{5 x}\right|_{x_{3}=0}=0 \\
& \left.M_{5 y}\right|_{x_{3}=0}=0 \\
& \left.Q_{5 z}\right|_{x_{3}=0}=0 \\
& \left.N_{6 x}\right|_{x_{3}=0}=0 \\
& \left.M_{6 y}\right|_{x_{3}=0}=0 \\
& \left.Q_{6 z}\right|_{x_{3}=0}=0 \\
& \left.u_{4}^{o}\right|_{x_{3}=L_{3}}=\left.u_{7}^{o}\right|_{x_{4}=0} \\
& \left.w_{4}\right|_{x_{3}=L_{3}}=\left.w_{7}\right|_{x_{4}=0} \\
& \left.\psi_{4}\right|_{x_{3}=L_{3}}=\left.\psi_{7}\right|_{x_{4}=0} \\
& \left.N_{4 x}\right|_{x_{3}=L_{3}}=\left.N_{7 x}\right|_{x_{4}=0}
\end{aligned}
$$




$$
\begin{aligned}
& \left.M_{4 y}\right|_{x_{3}=L_{3}}=\left.M_{7 y}\right|_{x_{4}=0} \\
& \left.Q_{4 z}\right|_{x_{3}=L_{3}}=\left.Q_{7 z}\right|_{x_{4}=0} \\
& \left.u_{5}^{o}\right|_{x_{3}=L_{3}}=\left.u_{8}^{o}\right|_{x_{4}=0} \\
& \left.w_{5}\right|_{x_{3}=L_{3}}=\left.w_{8}\right|_{x_{4}=0} \\
& \left.N_{5 x}\right|_{x_{3}=L_{3}}=\left.N_{8 x}\right|_{x_{4}=0} \\
& \left.Q_{6 z}\right|_{x_{3}=L_{3}}=\left.Q_{8 z}\right|_{x_{4}=0}=\left.M_{9 y}\right|_{x_{3}=L_{3}=0}=\left.\psi_{9}\right|_{x_{4}=0} \\
& \left.w_{6}^{o}\right|_{x_{3}=L_{3}=L_{3}}=\left.u_{9}^{o}\right|_{x_{4}=0} \\
& \left.N_{9 x}\right|_{x_{4}=0} \\
& w_{x_{4}=0}
\end{aligned}
$$

\section{Region 4}

$$
\begin{aligned}
& \left.N_{7 x}\right|_{x_{4}=L_{4}}=0 \\
& \left.M_{7 y}\right|_{x_{4}=L_{4}}=0
\end{aligned}
$$




$$
\begin{gathered}
\left.Q_{7 z}\right|_{x_{4}=L_{4}}=0 \\
\left.N_{8 x}\right|_{x_{4}=L_{4}}=0 \\
\left.Q_{8 z}\right|_{x_{4}=L_{4}}=0 \\
\left.u_{9}^{o}\right|_{x_{4}=L_{4}}=\left.u_{10}^{o}\right|_{x_{5}=0} \\
\left.w_{9}\right|_{x_{4}=L_{4}}=\left.w_{10}\right|_{x_{5}=0} \\
\left.\psi_{9}\right|_{x_{4}=L_{4}}=\left.\psi_{10}\right|_{x_{5}=0}=\left.Q_{10 z}\right|_{x_{5}=0} \\
\left.M_{9 y}\right|_{x_{4}=L_{4}=L_{4}}=\left.M_{10 y}\right|_{x_{5}=0} \\
\left.N_{10 x}\right|_{x_{5}=0}
\end{gathered}
$$

\section{Region 5}

$$
\begin{aligned}
& \left.u_{10}^{o}\right|_{x_{5}=L_{5}}=\left.u_{12}^{o}\right|_{x_{6}=0} \\
& \left.w_{10}\right|_{x_{5}=L_{5}}=\left.w_{12}\right|_{x_{6}=0} \\
& \left.\psi_{10}\right|_{x_{5}=L_{5}}=\left.\psi_{12}\right|_{x_{6}=0} \\
& \left.N_{10 x}\right|_{x_{5}=L_{5}}=\left.N_{12 x}\right|_{x_{6}=0}
\end{aligned}
$$




$$
\begin{aligned}
& \left.M_{10 y}\right|_{x_{5}=L_{5}}=\left.M_{12 y}\right|_{x_{6}=0} \\
& \left.Q_{10 z}\right|_{x_{5}=L_{5}}=\left.Q_{12 z}\right|_{x_{6}=0}
\end{aligned}
$$

\section{Region 6}

$$
\begin{gathered}
\left.N_{11 x}\right|_{x_{6}=0}=0 \\
\left.M_{11 y}\right|_{x_{6}=0}=0 \\
\left.Q_{11 z}\right|_{x_{6}=0}=0 \\
\left.N_{11 x}\right|_{x_{6}=L_{6}}=\frac{A_{11}^{U}}{A_{11}^{U}+A_{11}^{L}+E_{a} \eta} P \\
\left.M_{11 y}\right|_{x_{6}=L_{6}}=0 \\
\left.Q_{11 z}\right|_{x_{6}=L_{6}}=0 \\
\left.M_{12 x}\right|_{x_{6}=L_{6}}=\frac{A_{11}^{L}}{A_{11}^{U}+A_{11}^{L}+E_{a} \eta} P \\
\left.\right|_{x_{6}=L_{6}=L_{6}}=0 \\
=0
\end{gathered}
$$

